\title{
Cytokeratin 8: The Dominant Type II Intermediate Filament Protein in Lung Cancer
}

\author{
Nobuhiro Kanaji1 ${ }^{,}$, , Akihito Kubo ${ }^{2,}$, Shuji Bandoh ${ }^{1}$, Tomoya Ishii ${ }^{1}$, \\ Jiro Fujita ${ }^{3}$, Takuya Matsunaga ${ }^{1}$ and Etsuro Yamaguchi ${ }^{2}$ \\ ${ }^{1}$ Kagawa University \\ ${ }^{2}$ Aichi Medical University School of Medicine \\ ${ }^{3}$ University of the Ryukyus \\ Japan
}

\section{Introduction}

Lung cancer is the leading cause of cancer deaths worldwide. Cytokeratins (CKs) play an important role in cancer biology and circulating forms of CKs have been used as tumor markers in various malignancies. In the present chapter, the biological relevance of CKs and their release into the circulation are discussed, with a focus on CK8, a type II intermediate filament (IF) protein, and its association with type I CKs in lung cancer.

\subsection{Lung cancer}

Lung cancer is the most common cancer in the world, with an estimated 1.6 million new cases and 1.4 million deaths in 2008. In the United States, 222,000 new lung cancer cases and 157,000 deaths are estimated for 2010 (Jemal et al., 2011). More than four-fifths of all lung cancers are of non-small cell histology, comprised of adenocarcinomas (40-50\%), squamous cell carcinomas $(25-30 \%)$ and large cell carcinomas (10\%), while approximately $15 \%$ of lung cancers are of small cell histology.

Lung cancer is usually asymptomatic in its early developmental stages, and, even if symptomatic, the symptoms are often non-specific and unrelated to the early stage lung cancer. Accordingly, the majority of lung cancer patients are discovered at inoperable advanced stages. Between 1996 and 2003 in the United States, only 16\% of lung cancers were localized when diagnosed (compared with $91 \%$ of prostate cancers, $80 \%$ of melanomas and $61 \%$ of female breast cancers), $35 \%$ were locally advanced and $41 \%$ were metastatic (Youlden et al., 2008). Most likely because of the aggressive nature of the disease, the prognosis of lung cancer patients remains poor; ranging from a median survival time (MST) of 60 months and a 5 -year survival rate of $50 \%$ even for the earliest stage IA disease, to an MST of only six months and a 5 -year survival rate of as low as $2 \%$ in stage IV disease, based on the international database of cases that were classified according to the latest TNM staging system (version 7), which comprised 13,267 cases for clinical stage classification (Goldstraw et al., 2007).

* The co-first authors contributed equally to the work 
Compared with small cell lung cancer (SCLC), non-small cell lung cancer (NSCLC) is relatively insensitive to cytotoxic chemotherapy and radiotherapy, and surgical resection is highly recommended in the early stages of NSCLC. In locally advanced NSCLC that lies within the radiation field with curative intent, combined modality treatment with chest irradiation and systemic chemotherapy is the standard therapy. If curative thoracic irradiation is not applicable, such as in stage IV disseminated diseases, systemic chemotherapy is the standard care (NCCN.org, 2011).

SCLC is deemed to be a different entity from other lung tumors in terms of its origin, biological behavior, and clinical response to therapeutic interventions. SCLC, which is thought to originate from neuroendocine cells, is a rapidly growing aggressive tumor, and is rarely detected in its early operable stage. The MST of SCLC is mere 2-4 months if no positive treatment is applied (Rodriguez \& Lilenbaum, 2010; Simon \& Turrisi, 2007). In contrast to its extreme aggressiveness, SCLC is highly sensitive to radiation therapy and chemotherapy. Combination chemo-radiotherapy is the most effective treatment for patients with SCLC of limited extent, whose tumor lies within a radiation field of curative radiotherapy (limited disease, LD), and results in an objective response rate of $80-90 \%$ (ORR; $\%$ of patients who achieved $\geqq 50 \%$ tumor volume reduction), an MST of $14-20$ months and a 2-year survival rate of $20-40 \%$. However, only palliative chemotherapy is applicable as a positive treatment for patients with disseminated SCLC (extensive disease, ED). ORR, MST and the 2-year survival rate of patients with ED-SCLC are 60-70\%, 7-10 months and only less than 5\%, respectively(Rodriguez \& Lilenbaum, 2010; Simon \& Turrisi, 2007).

\subsection{Cytokeratins and lung cancer}

The cytoskeleton is composed of three different classes of proteins, with different filament diameters: actin microfilaments, tubulin microtubules, and intermediate filaments (IFs) (Quinlan et al., 1985). IF proteins, which are chemically stable filaments of $\sim 10 \mathrm{~nm}$ in diameter, constitute cytoskeletal systems in the cytoplasm of most eukaryotic cells. CKs are typical IF proteins that are expressed in a highly epithelial cell-type specific manner. CKs constitute the largest family of proteins, and are subdivided into "acidic" type I (CK9-CK23) and "basic or neutral" type II (CK1-CK8) subclasses (Moll et al., 2008; Moll et al., 1982). These CK subclasses are expressed in epithelial cells in various combinations and form obligate heteropolymers of type I and type II CKs in a tissue- or cell type-specific manner. The dominant IFs expressed in epithelial cells in the respiratory tract are CK8 and CK18, and other type II CKs (5, 6 and 7) as well as type I CKs (17 and 19) are expressed to various extents. CK8 and CK18 expression persists in most carcinomas, whereas other CKs tend to be expressed at lower levels or are lost during tumor progression (Coulombe \& Omary, 2002; Oshima, 2002).

The biological functions of CKs, including scaffolding and the maintenance of tissue integrity, have been elucidated through gene knockout studies (Coulombe \& Omary, 2002). In addition, CKs play a role in regulating tumorigenesis and tumor invasion in a complex and not yet fully determined manner. Several research groups have reported that coexpression of CK8, CK18 and type III IF vimentin confer highly invasive phenotypes on various tumors (Chu et al., 1993; Chu et al., 1996; Chu et al., 1997; Yamashiro et al., 2010). 
However, observations that are apparently contradictory to those mentioned above have also been reported; decreased expression of type I CKs significantly correlated with tumor progression or increased invasion ability in several other tumor types (Buhler \& Schaller, 2005; Crowe et al., 1999; Woelfle et al., 2004). The epithelial-mesenchymal transition (EMT) is an embryonic developmental program that is also observed during tumor progression in a variety of cancer types, suggesting that the EMT confers, or potentiates, invasiveness of tumor cells (Takeyama et al., 2010). The roles of CKs in tumor invasion and in the EMT are further discussed later in this chapter.

Although IFs have been assumed to form highly insoluble cytoskeletal networks, CKs are also found in the tumor as well as in the blood, where they have been thought to circulate as a partially degraded complex, which has led to their use as potential tumor markers (Buccheri \& Ferrigno, 2001).

Circulating fragments of CK8, CK18 or CK19, such as tissue polypeptide antigen (TPA), tissue polypeptide specific antigen (TPS), Cyfra 21-1, and caspase-cleaved CK18, have been used as tumor markers of various epithelial malignancies (Buccheri \& Ferrigno, 2001; Kramer et al., 2004; Pujol et al., 1993). Tumor markers targeting single type I CKs in the systemic circulation have been evaluated: e.g., CK18 as a traditional TPS, caspase-cleaved CK19 as Cyfra 21-1, and the recently developed caspase-cleaved CK18 (M30) as well as total CK18 (M65) (Kramer et al., 2004; Linder et al., 2010). While circulating type II CKs had not been reported as tumor markers targeting single CK origin, we observed that serum levels of a type II CK8 were significantly associated with tumor progression and shortened survival in patients with NSCLC. In the later part of this chapter, we also review the biological relevance and clinical significance of circulating CK-related forms.

\section{Expression of cytokeratins in lung cancer}

While CKs are expressed in a tissue- or cell-type preferential manner, their expression is also significantly influenced by the differentiation as well as the functional status of cells in a given environment. The expression of IFs in various types of malignant tumors has been extensively evaluated. In most cases, epithelial cancers maintain the characteristic CK expression patterns of the respective tissues and organs from which the cancers were derived. This characteristic enables the use of CKs as diagnostic tools for analysis of tumor pathology (Karantza, 2011; Moll et al., 2008).

\subsection{Cytokeratin networks}

All eukaryotic cells express actin and tubulin, whereas cytoplasmic IF, the third class of cytoskeletal protein, is only expressed in some metazoans. For example, animals with dermoskeleton usually do not express cytoplasmic IFs. Even in vertebrates, oligodendrocytes, which are a specific type of nerve sheath cell in the central nervous system, do not express such IFs. In cells that do express cytoplasmic IFs, IF proteins have been considered to have an important role in protecting cells from various stresses by adding mechanical strength to the cells.

Nuclear lamins, the so-called type V IF proteins, are believed to be the evolutionary progenitors of the largest family of IF proteins. Lamins are the main structural components 
of a cage-like structure called the lamina, which is situated underneath the inner nuclear membrane. Although the lamina has quite a different architecture from cytoskeletal networks which are three dimensional and highly branched, the lamina also provides strength to the inner nuclear membrane and supports the shape of the nucleus. Lamin genes are thought to have duplicated several times during metazoan evolution, and these duplicated genes eventually evolved to produce cytoplasmic IFs (Alberts et al., 2008; Hutchison, 2002).

An individual CK subunit is composed of extended CK molecules, each with a central $\alpha$ helical domain that forms a parallel "coiled-coil" with a CK of the other type (i.e., a type I type II heterodimer; see also "4. Extracellular Release of Cytokeratins" and Fig. 6). Two CK heterodimers then associate in an antiparallel offset fashion to form a staggered tetramer that associates with another tetramer for further extension of molecules. The tetramer constitutes the soluble CK subunit that is analogous to the actin monomer, or to the $\alpha \beta$ tubulin dimer. The tetramers pack together laterally to form a filament of $10 \mathrm{~nm}$ in diameter, which is composed of eight parallel protofilaments assembled from CK tetramers. The large number of polypeptides within the CK filaments has strong lateral hydrophobic interactions that are typical of coiled-coil proteins, which gives CK filaments both elasticity and stability (Alberts et al., 2008).

CK filaments confer mechanical strength to animal cells. Cross-linked keratin networks that are fixed by disulfide bonds exhibit an almost infinite stability, as seen in the outer layer of skin, hair, nails, claws and scales. One single epithelial cell may express multiple types of CKs, and these CKs copolymerize into a single network. CK filaments impart mechanical stability to epithelial tissues in part by anchoring CK filaments at sites of cell-cell contact, called desmosomes, or of cell-matrix contact, called hemidesmosomes (Alberts et al., 2008; Fuchs \& Karakesisoglou, 2001).

\subsection{Cytokeratin 8 and cytokeratin $\mathbf{1 8}$ are the dominant intermediate filament proteins in non-small cell lung cancer}

The pair of type II CK8 and type I CK18 is the first CK pair to be detected in early embryonic development. CK8 and CK18 are typically co-expressed and form the primary CK heterodimers in virtually all simple epithelia (one-layered epithelial cells): respiratory epithelia; gastrointestinal epithelia; parenchymatous epithelia including hepatocytes, pancreatic acinar cells, and renal tubular cells; as well as ductal epithelia of parenchymatous organs including bile ducts, renal collecting ducts, and pancreatic ducts. In some types of epithelial cells, e.g., hepatocytes in the liver and acinar cells of the pancreas, the CK8/CK18 pair is the only CK pair expressed. As stated above, CK8 and CK18 are the dominant CK pair in epithelial cells in the respiratory tract, where type II CKs (5, 6 and 7) as well as type I CKs (17 and 19) are also expressed. CK8 and CK18 are CK types that tend to persist in most epithelial cancers (Moll et al., 2008).

Figure 1 shows representative expression patterns of IF proteins in a panel of various cancer cell lines of epithelial and non-epithelial origins, including lung cancer (NSCLC and SCLC), mesothelioma (cancer that develops from the mesothelium, the sac lining the internal body cavities), liver cancer (hepatocellular carcinoma), colorectal cancer, breast cancer, tumors of 
T lymphocyte- and B lymphocyte-origins, and a fibroblast-like cell line. We quantified the absolute expression levels of CKs by quantitative immunoblotting (Fig. 1, A and B).

While all NSCLC cell lines express abundant CK8 and CK18 that form the dominant CK pair ( $\sim 40$ pmol per $10^{6}$ cells on average), three out of seven SCLC lines do not express detectable levels of CK8 and CK18, and even when expressed in SCLC, the levels of both CKs were lower than those of NSCLC cells. CK7 and CK19 are usually expressed at lower levels than CK8 and CK18 (respectively $\sim 5$ and $\sim 20$ pmol per $10^{6}$ cells on average), and are expressed only in a limited number of lung cancer cell lines. None of seven SCLC lines that we screened expressed CK7. Similarly, type I and type II CK messenger RNA (mRNA) expression was previously reported to be higher in NSCLC than SCLC cells (Fukunaga et al., 2002; Ueda et al., 1999). Regarding CK19 expression, two cell lines, HI1017 adenocarcinoma and Lu135 SCLC, do not express CK19 because of a point mutation in the promoter region (at $-99, \mathrm{G}$ to C) of the CK19 gene (Fujita et al., 2001). None of the lung cancer cell lines in the panel expressed CK20, which expression was only detected in colorectal cancer cell lines. Other CKs (CK4, CK5, CK6, CK13 and CK17) were not expressed in any lung cancer cell line that we tested (data not shown). These CKs are assumed to be CKs of stratified epithelia (Moll et al., 2008).

NSCLC and SCLC also exhibit differential expression patterns of IF proteins other than type I and type II CKs. Vimentin is a type III IF protein that is expressed in mesenchymal tissues and is presumed to be important for stabilizing the architecture of the cytoplasm. The lymphoid tumors, fibroblast-like cells, and mesothelioma cells tested by immunoblotting all expressed vimentin, as shown in Fig. 1A. The vimentin protein was also detectable by immunoblotting in seven out of 12 NSCLC lines but was not detected in any of the SCLC lines. The absolute expression level of vimentin was $9.8 \mathrm{pmol} / 10^{6}$ cells on average, approximately one-fourth that of CK8 and CK18. Vimentin was previously reported to be expressed in only $\sim 10 \%$ of variant type SCLCs and $\sim 90 \%$ of pure SCLCs do not express vimentin (Broers et al., 1986).

Lamins, which are type V IF proteins, are components of the nuclear lamina, an IF network that underlies the inner nuclear membrane and determines the size and shape of the nucleus. Three types of lamins, A, B and C, have been described in mammalian cells (Hutchison, 2002). Lamin A and lamin C, with molecular masses of $74 \mathrm{kDa}$ and $65 \mathrm{kDa}$ respectively, arise from a single gene by alternative splicing (Fisher et al., 1986; McKeon et al., 1986). B-type lamins are represented by lamin B1 and lamin B2 in vertebrates. While Atype lamins are expressed in a developmentally controlled manner, B-type lamins are expressed in all types of cells. Broers examined 22 lung cancer cell lines and 46 fresh frozen lung cancer specimens and reported that B-type lamins were expressed in all of the different cell lines examined, whereas A-type lamins were expressed in all tested NSCLC lines but were absent, or only weakly expressed in 14 out of 16 SCLC cell lines (Broers et al., 1993). Our data confirmed the results of Broers et al.; whereas NSCLCs express lamin A and lamin $C$ at a higher level than SCLCs, lamin B was detected in all cell lines tested. We also noticed that the expression level of lamin B, as determined by quantitative immunoblotting, was significantly higher in SCLC than in NSCLC (mean \pm SD, $1.31 \pm 0.25$ vs. $0.66 \pm 0.26$, arbitrary units normalized by the intensity of Coomassie staining, $\mathrm{p}<0.05$ ). 


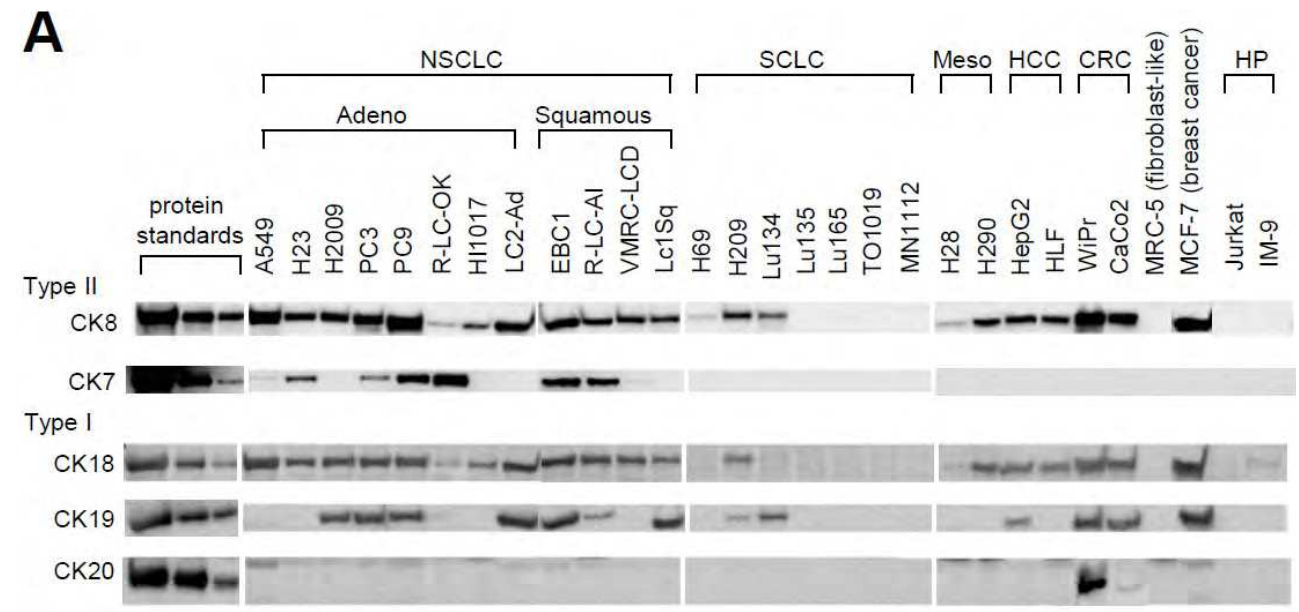

Type III

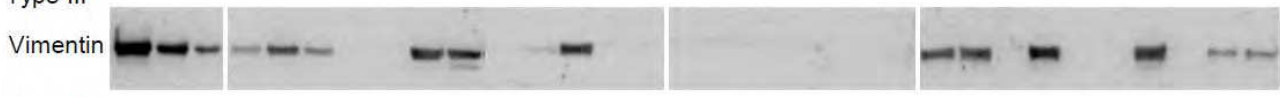

Type V
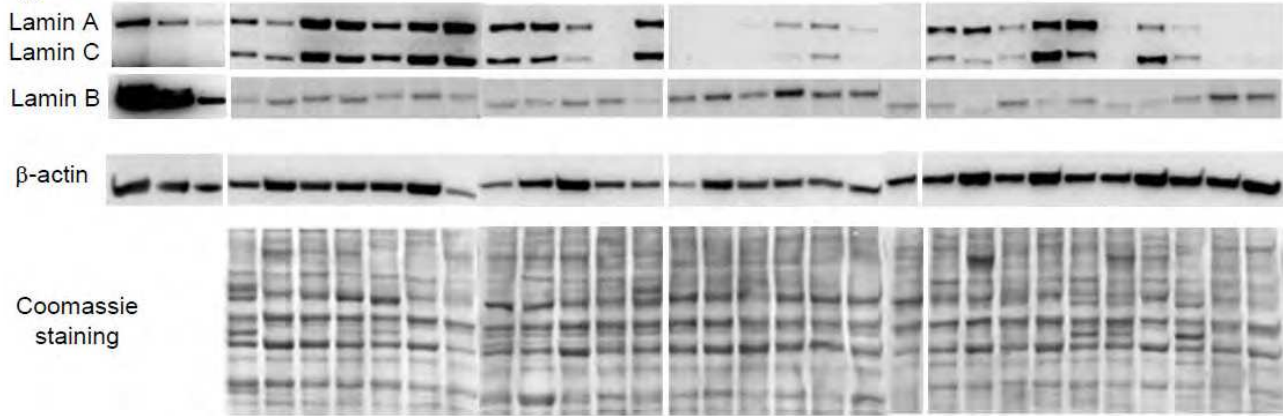

B
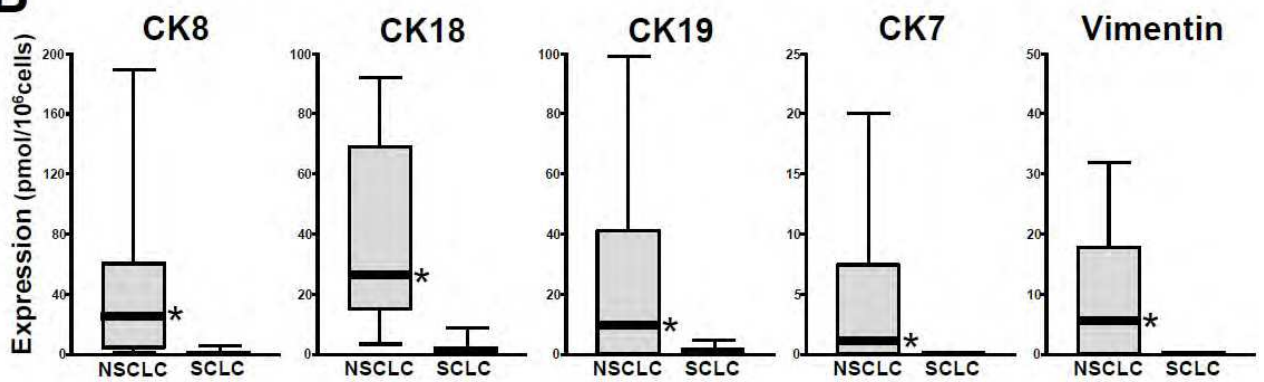

(A) Quantitative immunoblotting of IFs in NSCLC, SCLC and non-lung cancer cell lines. Of the 19 lung cancer cell lines assayed (12 NSCLC lines; 8 adenocarcinomas, 4 squamous cell carcinomas, and 7 SCLCs), the HI1017, TO1019 and MN1112 lines were established at Kagawa University. The other lung cancer and non-lung cancer cell lines were obtained from the Japan Cancer Research Bank (Tokyo, Japan). The antibodies used were K8.8 (CK8; Neomarkers, Fremont, CA, USA), RCK105 (CK7), Ks18.04 
(CK18), Ks19.02 (CK19), Ks20.8 (CK20, all from Progen, Heidelberg, Germany), CIT605 (vimentin, YLEM, Rome, Italy), sc7292 (lamin A/C, Santa-Cruz Biotechnology, Santa Cruz, CA, USA), X223 (nuclear lamin B, Progen), AC-15 ( $\beta$-actin, Sigma-Aldrich, St Louis, MO, USA), and anti-mouse immunoglobulin G (IgG) conjugated with horseradish peroxidase (HRP; Santa Cruz Biotechnology). Purified protein standards were purchased from Progen. Exponentially growing cells were lysed in $1 \times$ sample buffer $(62.5 \mathrm{mM}$ Tris$\mathrm{HCl} \mathrm{pH} \mathrm{6.8,} \mathrm{2.15 \%} \mathrm{SDS,} \mathrm{5 \%} \beta$-mercaptoethanol, 15\% glycerol), and subjected to sodium dodecyl sulfatepolyacrylamide gel electrophoresis (SDS-PAGE) followed by immunoblot analyses using specific antibodies and enhanced chemiluminescence. The PVDF membranes used for immunoblotting were stained with Coomassie Brilliant blue dye to normalize specific signal intensity in immunoblotting. Representative blots of at least three independent experiments are shown.

(B) Absolute expression levels of IF proteins in NSCLC versus SCLC.

The intensity of positive signals in immunoblot analyses was quantified densitometrically using NIH Image version 1.62 (http:/ / rsb.info.nih.gov/nih-image/download.htm). The quantified signal intensities were then compared with those of protein standards at known concentrations. Boxplots indicate median values, ranges of $25-75$ percentile and total ranges. ${ }^{*} p<0.05$ compared with SCLC. Adeno, adenocarcinoma; Squamous, squamous cell carcinoma; Meso, mesothelioma; HCC, hepatocellular carcinoma; CRC, colorectal carcinoma; HP, hematopoietic tumors.

Fig. 1. Expression of IFs in non-small cell lung cancer (NSCLC), small cell lung cancer (SCLC) and non-lung cancer.

\subsection{Mechanisms for maintaining cytokeratin filament networks}

Compared with the intensively studied actin filaments or microtubules, the mechanism of assembly and disassembly of IFs is not well understood. However, several types of IFs exhibit a highly dynamic structure in metazoan cells. Type III vimentin is probably the most intensively studied cytoplasmic IF. Similar to the mechanism by which phosphorylation regulates the disassembly of nuclear lamins, vimentin structures also disassemble during the mitosis phase of the cell division cycle following specific phosphorylation of vimentin at its amino-terminus by cyclin-dependent kinase 1 (Chou et al., 1990; Sihag et al., 2007). Phosphorylation is also considered to alter the solubility of IF proteins including both types of CKs (Ku et al., 2002; Liao \& Omary, 1996). One of the IF-interacting proteins, 14-3-3 is involved in $\mathrm{CK}$ solubilization during mitosis by binding to the phosphorylated serine residue (Ser 33) of CK18 (Ku et al., 2002).

A single epithelial cell often express more than two types of CKs, and all of these CKs copolymerize into a single CK network. One good example of such copolymerization is seen in lung cancer NSCLC cells. Since NSCLC cells originate from the respiratory tract, they express CK8 and CK18 as their primary CK pair and also frequently express CK7 and CK19 as their secondary CKs (Fig. 1, A). These observations raise the question as to why one cell expresses multiple type I and type II CKs. One can easily hypothesize that multiple CKs would compensate for each other if expression of a particular CK was disrupted. We show the results of simple experiments to test this hypothesis (Fig. 2. Modified with permission from (Kanaji et al., 2007)).

A549 cells express CK8 and CK18 as the dominant CK pair and also express CK7 at a lower level and CK19 at a minute, trace level. Roughly equimolar amounts of type I and type II CKs are expressed in these cells (Fig. 2, A), which is consistent with previous observations (Kim et al., 1984). In this simplistic model, we regarded CKs as being in a filament form (i.e., 
insoluble), although a small fraction $(\sim 5 \%)$ of the total CK has been reported to be soluble (Chou et al., 1993). This model implies that the dominant type I/type II CK pair (depicted as large discs) likely plays a central role in the formation of CK networks. For example, CK8/CK18 seems to be the most important pair in A549 cells, whereas CK8/CK19, CK7/CK18, and CK7/CK19 are present as minor pairs. Based on these observations we also hypothesized that maintenance of the dominant CK pair is critical for the integrity of CK networks. Thus, a decrease in a dominant CK of one type, may also lead to decreases in CKs of the complementary type because of filament instability. Furthermore, if levels of a dominant CK decrease, another CK of the same type would increase to prevent disruption of the CK network. To test these hypotheses, RNA interference was used to knockdown expression of CK genes in this cell line.

A

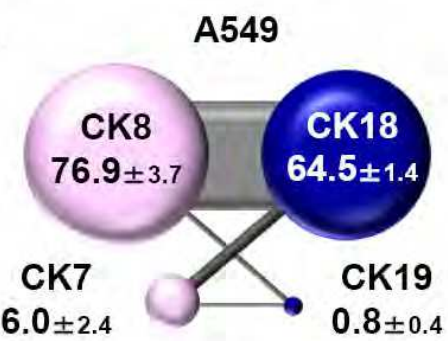

C CK8, moderate suppression

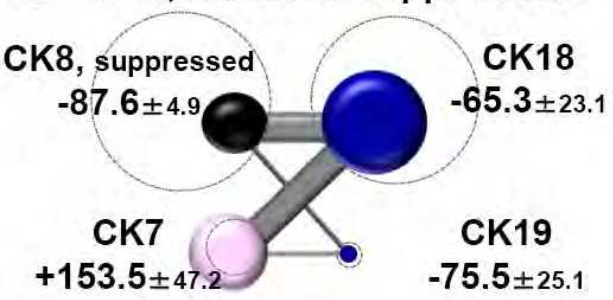

B CK18, moderate suppression

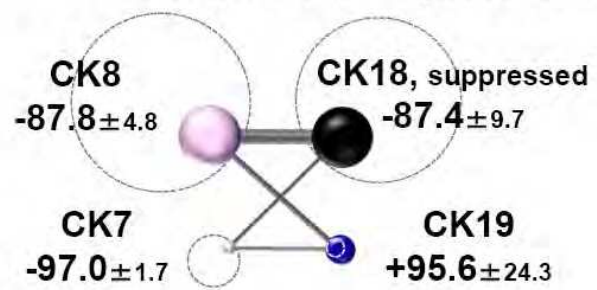

D CK8, severe suppression

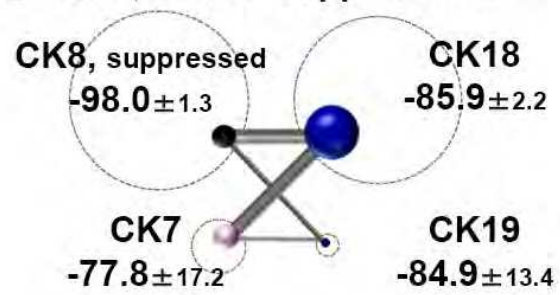

(A) Schematic outline of the experiment. The expression levels of CK proteins in the NSCLC A549 cell line were evaluated by quantitative immunoblotting. CK protein levels are shown as means \pm S.D. (pmol/106 cells) of three independent experiments. The thickness of the lines connecting type I and type II CKs represents their putative binding capacities based on the calculated molar ratios of CKs of each CK type. (B-D) CK levels and putative binding were similarly measured after CK gene suppression by RNA interference. CK protein levels following RNA interference were quantified and are shown compared with those of parent cells (transfection with control short interfering RNA; dotted circle). The black discs represent expression levels of CKs targeted by specific RNA interference. Numbers are \% changes of expression levels from those of control cells (mean \pm S.D.).

Fig. 2. Quantitative evaluation of type I and type II CKs upon single CK suppression

When expression of the type I CK18 was knocked-down to a moderate degree (Fig. 2, B), protein expression of both of the type II CKs, CK8 and CK7, was also considerably suppressed. In contrast, a slight but clear increment in protein expression of the other type I CK, CK19, was detected, suggesting compensatory up-regulation of the non-targeted CK19. We confirmed that only the mRNA expression of CK18, and not that of other CKs, was 
severely diminished following RNA interference targeting of CK18, indicating that the changes in the protein expression of CK8, CK7 and CK19 were changes at the protein level and were not due to off-target effects of the short interfering RNA (siRNA) that targeted CK18. Similarly, when type II CK8 was suppressed to a moderate degree (Fig. 2, C), protein expression of both of the type I CKs, CK18 and CK19, was decreased but, conversely, the type II CK7 was up-regulated, at the protein level, thereby decreasing the damage on total type II CKs. However, this compensatory mechanism that maintained total CK integrity was almost completely disrupted when expression of the dominant CK8 was severely suppressed (Fig. 2, D).

Therefore, to maintain properly functioning CK networks, there appears to be a requirement for a certain "threshold" level of expression of a single dominant CK. If the expression level of the dominant CK is lower than this threshold, then type I-II pairing, and, accordingly, elongation of IF protofibrils or filaments, cannot occur and CK networks cannot be formed. Redundant expression of multiple CKs seems to be advantageous for the stabilization of CK networks, and the above observations may explain, at least in part, why a single cell expresses multiple type I and type II CKs (Kanaji et al., 2007).

\section{Cytokeratins in tumor invasiveness and epithelial-mesenchymal transition}

\subsection{Relationship between cytokeratin expression levels and cancer invasiveness}

Several functions of CKs, including roles in scaffolding and tissue integrity, have been demonstrated in normal tissues using gene knockout studies (Coulombe \& Omary, 2002; Karantza, 2011; Moll et al., 2008). In addition, it has been reported that CKs play a role in the regulation of cancer cell invasion, metastasis and tumorigenesis (Buhler \& Schaller, 2005; Chu et al., 1993; Chu et al., 1996; Chu et al., 1997; Crowe et al., 1999; Hendrix et al., 1992; Kanaji et al., 2011; Schaller et al., 1996; Woelfle et al., 2004; Yamashiro et al., 2010). Table 1 summarizes published studies that describe the correlation of endogenous CK expression with cancer invasiveness.

\begin{tabular}{|l|l|l|l|}
\hline Author, year & Cancer type & $\begin{array}{l}\text { Endogenous CKs } \\
\text { expressed }\end{array}$ & $\begin{array}{l}\text { Invasive or } \\
\text { metastatic phenotype }\end{array}$ \\
\hline Hendrix, 1992 & Melanoma (cell lines) & CK8 and 18 & High \\
\hline Schaller, 1996 & $\begin{array}{l}\text { Breast cancer } \\
\text { (clinical tumors and cell lines) }\end{array}$ & CK18 & Low \\
\hline Chu, 1997 & Lung adenocarcinoma (cell line) & CK8 and 18 & High \\
\hline Crowe, 1999 & $\begin{array}{l}\text { Oral squamous cell carcinoma } \\
\text { (cell line) }\end{array}$ & CK19 & Low \\
\hline Woelfle, 2004 & Breast cancer (patients) & CK18 & Longer survival \\
\hline $\begin{array}{l}\text { Yamashiro, } \\
2010\end{array}$ & $\begin{array}{l}\text { Cutaneous squamous cell } \\
\text { carcinoma (patients) }\end{array}$ & CK8 and 18 & High \\
\hline Kanaji, 2011 & Lung adenocarcinoma (cell lines) & CK7, 8, 18 and 19 & Low \\
\hline
\end{tabular}

Table 1. Correlation of endogenous CK expression with cancer invasiveness 
In 1992, expression levels of CK8 and CK18 were determined in nine human melanoma cell lines expressing vimentin. The expression of CK8 and CK18 was below the level of detection in the poorly metastatic A375P cell line, was at a low level in the moderately metastatic A375M line, and displayed the highest level in the highly metastatic C8161 line (Hendrix et al., 1992). Subpopulations of the human lung adenocarcinoma cell line CL1 were selected according to their invasive ability that was assessed using a Transwell invasion chamber assay. These subpopulations showed a 4- to 6-fold increase in their ability to invade a basement membrane matrix over that of their parental cells and expressed higher levels of the $92 \mathrm{kDa}$ gelatinase, vimentin, CK8 and CK18. In addition, clonal isolation of anti-CK18-antibody-positive and negative cell populations demonstrated that expression of CK18 correlated with their enhanced invasive ability (Chu et al., 1997). CK8 and 18 are not expressed in normal keratinocytes. However, both CKs are co-expressed in a metastatic derivative of a transformed mouse keratinocyte cell line in which they formed CK8/18 filaments (Yamashiro et al., 2010). In addition, analysis of specimens from 21 pre-invasive and 24 invasive cutaneous squamous cell carcinomas (cSCCs) derived from patients indicated that ectopic CK8/18 coexpression was almost exclusively detected in invasive cSCCs (Yamashiro et al., 2010).

In contrast, several reports have shown an inverse correlation between CK expression levels and cancer invasiveness or progression. Oral squamous cell carcinoma (SCC) lines that did not express CK19 were significantly more invasive in vitro than those which retained CK19 expression (Crowe et al., 1999). CK18 protein expression was low in highly metastatic breast cancer cell lines, but, conversely, was high in weakly metastatic cell lines (Schaller et al., 1996). We have recently established invasive sublines of NSCLC adenocarcinoma cells, HI1017 and A549, by repeated selection of invasive cells using Matrigel, a membrane invasion chamber system (Kanaji et al., 2011). In this in vitro invasion assay, invasive sublines of these cells showed very much higher invasive ability compared with that of the parental HI1017 and A549 cells (>100-fold and 50-fold, respectively, $p<0.01$ ) as shown in Fig. 3 (Figures 3-5. Modified with permission from (Kanaji et al., 2011)). These invasive sublines showed lower CK expression levels than their parental cells.
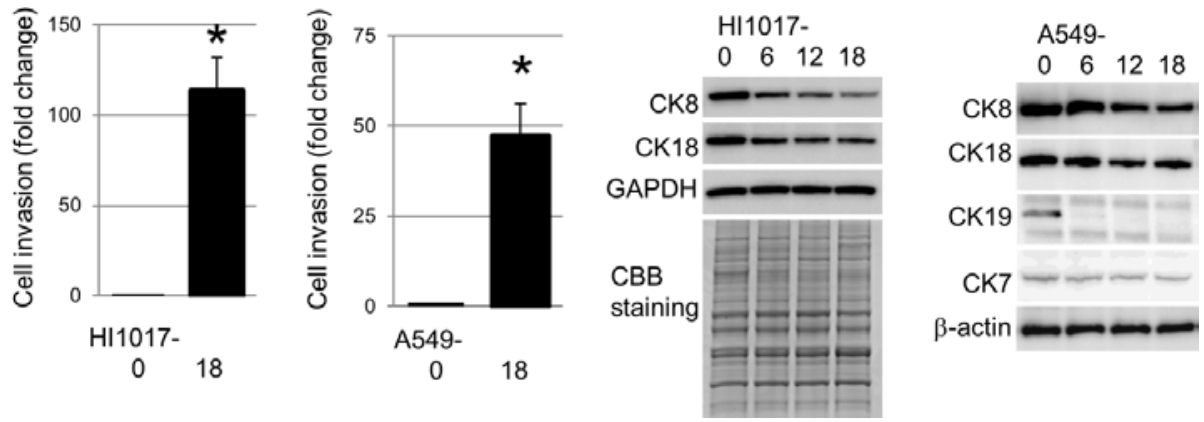

Highly invasive sublines of the NSCLC cell lines, HI1017 and A549, designated as HI1017-18 and A54918 respectively, were selected by repeated assay (up to 18 times) of cell invasion, which was assessed using an in vitro invasion assay with Matrigel-coated membranes. CK expression was determined by quantitative immunoblotting as described in Fig. 1. Repeated MICS-selection of HI1017 and A549 cells resulted in decreased CK expression levels. HI1017-18 and A549-18 show lower CK expression levels than their respective parental cells (HI1017-0 and A549-0). * $p<0.01$ compared with HI1017-0 or A549-0.

Fig. 3. Increased invasive ability and decreased CK expression of cells selected using a Matrigel membrane invasion chamber system (MICS). 
The correlation between CK expression and survival has also been examined. CK18 protein expression was immunohistochemically examined using paraffin sections of primary breast carcinoma tumors from 134 patients. The mortality rate was $4.5 \%$ in the CK18 immunostaining-positive group and $44.6 \%$ in the CK18-negative group during an 8-year follow up period. CK18 expression was an independent and significant predictor for overall survival by a multivariate analysis (Schaller et al., 1996). Woelfle et al. evaluated the expression pattern of CK18 in 1,458 primary breast cancers by immunohistochemical analysis using a high-density tissue microarray. CK18 expression was similarly downregulated in $25.4 \%$ of human breast cancers compared to normal breast tissues. Downregulation of CK18 significantly correlated with advanced tumor stages and pathologically higher grades. Kaplan-Meier survival analysis revealed that CK18 expression was a prognostic indicator of both overall survival $(p=0.015)$ and cancer-specific survival $(p=0.005)$. Based on the correlation between tumor CK18 expression and patient prognosis the authors concluded that low CK18 expression may be an indicator of poor prognosis and that CK18 might suppress tumor progression (Schaller et al., 1996).

\subsection{Altered expression levels of cytokeratins and cancer invasiveness}

Table 2 summarizes published studies that analyzed the effect of CK inhibition or overexpression on invasive or metastatic phenotypes of cancer cell lines

\begin{tabular}{|l|l|l|l|}
\hline Author, year & Cancer type & $\begin{array}{l}\text { Manipulation of CK } \\
\text { expression }\end{array}$ & $\begin{array}{l}\text { Change in invasive } \\
\text { or metastatic } \\
\text { potential }\end{array}$ \\
\hline \hline Hendrix, 1992 & Melanoma & Inhibition of CK18 & Decreased \\
\hline Chu, 1993 & Mouse fibroblast & Induction of CK8 and 18 & Increased \\
\hline Chu, 1996 & Melanoma & Induction of CK8 and 18 & Increased \\
\hline Crowe, 1999 & Oral squamous cell & Induction of CK19 & Decreased \\
& carcinoma & & Decreased \\
\hline Bühler, 2005 & Breast cancer & Induction of CK18 & Decreased \\
\hline Kanaji, 2011 & Lung adenocarcinoma & Induction of CK19 & Increased \\
\cline { 3 - 4 } & & Inhibition of CK8 and 18 & \\
\hline
\end{tabular}

Table 2. Effect of modification of CK expression on cancer invasiveness

Disruption of CK in human melanoma cells by transfection with a mutant CK18 complementary DNA (cDNA) resulted in decreased invasive and metastatic potential that directly correlated with a reduction in migratory activity (Hendrix et al., 1992). Mouse L cells, which are fibroblasts that express vimentin, were transfected with both CK8 and 18 . Cells that expressed exogenous CK8/18 filaments showed a higher migratory activity on, and higher ability to invade, extracellular matrix-coated filters compared with the parental and control-transfected clones. Furthermore, a heterogeneous population of L clones that were selected using serial migration assays were enriched in CK-positive cells (Chu et al., 1993). An A375P human melanoma cell line that expressed vimentin and had low invasive ability was transfected with CK8 and CK18 cDNA. The resultant stable transfectants that 
expressed vimentin and the two CKs, showed a two to three-fold increase in their invasion of basement membrane matrix and migration through gelatin in vitro compared to nontransfected cells (Chu et al., 1996). Similarly, Yamashiro et al also reported that coexpression of exogenous CK8 and CK18 conferred invasiveness to the parental non-metastatic transformed mouse keratinocyte line (Yamashiro et al., 2010).

In contrast, there have been several reports that overexpression of $\mathrm{CKs}$ can reduce cancer invasiveness. Stable expression of CK19 cDNA in CK19 negative SCC cell lines of the head and neck altered cell morphology and intercellular adhesiveness, and significantly decreased the number of cells able to migrate through a reconstituted basement membrane (Crowe et al., 1999). A dramatic reduction in the aggressiveness of the breast cancer cell line MDA-MB-231 was observed following forced CK18 expression (Buhler \& Schaller, 2005). We transfected exogenous CK19 cDNA into the lung adenocarcinoma cell line HI1017 that lacks endogenous CK19 (Kanaji et al., 2011). The resulting CK19-expressing clones showed lower invasive ability than mock-transfected cells (Fig. 4).

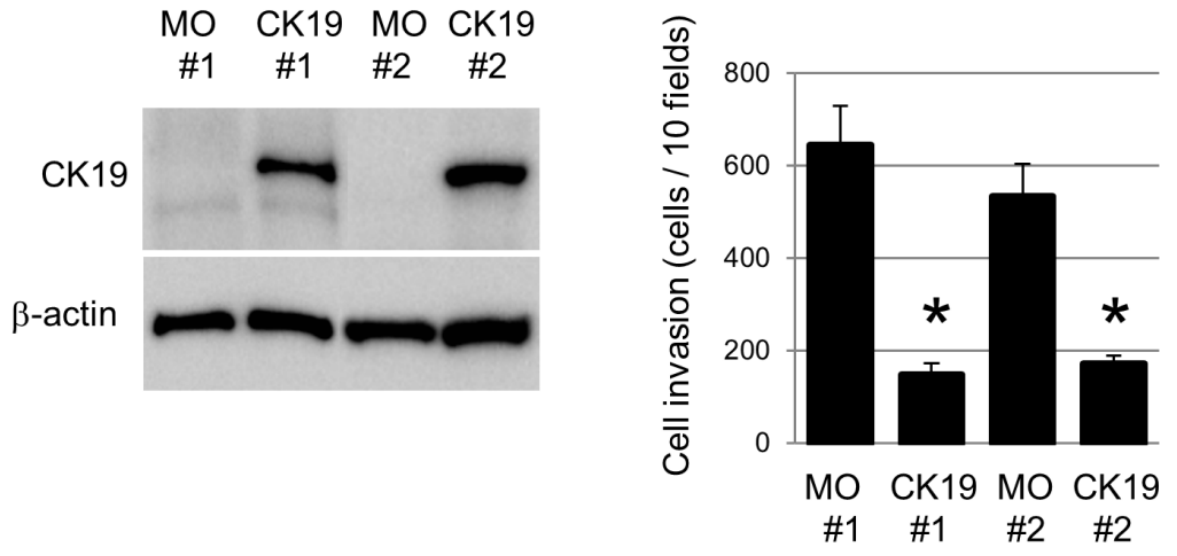

(Left) Western blotting of CK19 expression in stable HI1017 clones \#1 and \#2 expressing exogenous CK19. (Right) Invasion assay. Data are means \pm S.D. of three independent experiments. ${ }^{*} p<0.01$ compared with mock (MO) transfections.

Fig. 4. Exogenous CK19 inhibits the invasive phenotype.

In addition, suppression of either CK8 or CK18 by short interfering RNAs led to a decrease in total CKs and increased invasiveness of both of HI1017 and A549 cell lines (Fig. 5, (Kanaji et al., 2011)).

These apparently contradictory observations regarding CK expression and tumor progression might suggest that CKs may function differently depending on the tissue and the cellular context. Another important IF protein which may affect invasive ability is vimentin. Invasive lung cancer cell lines strongly expressed vimentin as well as CKs (Chu et al., 1997). Interestingly, forced CK18 expression was associated with a complete loss of vimentin in a breast cancer cell line and resulted in a reduced malignant potential (Buhler \& Schaller, 2005). Therefore, in addition to the expression level of CKs, the negative correlation of CKs and vimentin could also play an important role in cancer invasion. 

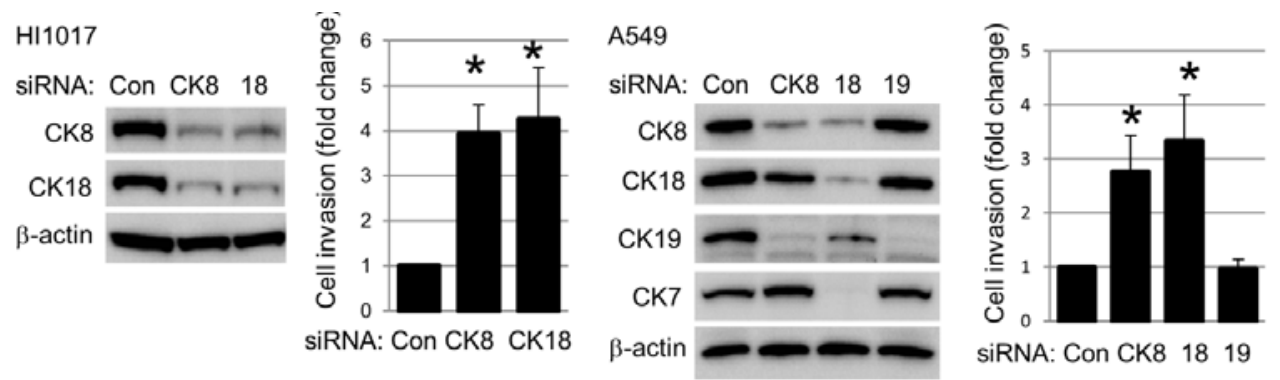

HI1017 and A549 cell lines were transfected with siRNA targeting CK8, CK18 or CK19 and were subjected to an invasion assay and to immunoblotting to confirm silencing efficacy. ${ }^{*} p<0.05$ compared with control siRNA (Con).

Fig. 5. Inhibition of CK8 and 18 results in a decrease in invasive ability of lung cancer cell lines.

\subsection{Epithelial-mesenchymal transition (EMT) and cytokeratins}

A developmental regulatory program, referred to as the "epithelial-mesenchymal transition" (EMT), has been strongly suggested to be a mechanism by which transformed epithelial cells can acquire the ability to invade, to resist apoptosis and to disseminate. Indeed EMT traits have been reported to be involved in embryonic development and to confer invasiveness to cancer cells during the progression of cancer (Hanahan \& Weinberg, 2011; Takeyama et al., 2010). Various types of factors have been reported to induce EMT, including cytokines, growth factors and anti-cancer drugs (Kasai et al., 2005; Li et al., 2009; Shih \& Yang, 2011; Yee et al., 2010). In A549 lung adenocarcinoma cells, which retain the properties of type II lung alveolar epithelial cells, EMT was induced by transforming growth factor- $\beta 1$ (TGF- $\beta 1$ ), and this induction was accompanied by morphological change into a spindle fibroblast-like shape, an increase in mesenchymal markers including vimentin, fibronectin, collagens I and III, and connective tissue growth factor (CTGF), and a decrease in epithelial markers including E-cadherin and CK19 (Kasai et al., 2005). Doxorubicin could induce EMT in cells of the breast cancer cell line MCF7, which also retain several characteristics of differentiated mammary epithelium, as evidenced by doxorubicin-mediated increases in alpha-smooth muscle actin ( $\alpha$-SMA) and vimentin and decreases in E-cadherin and CK19 (Li et al., 2009). Similarly, down-regulation of the epithelial markers E-cadherin and CK8 and 18 was observed in EMT-induced prostate cancer cells (Yee et al., 2010). In addition to the down-regulation of several epithelial markers of differentiation such as E-cadherin, CKs were also down-regulated during the EMT process in these types of tumors.

Down-regulation of CKs may also be related to EMT in clinical colorectal tumors. Knosel et al have recently reported that a low CK expression level correlates with a shortened survival time. Using tissue microarrays comprised of 468 colorectal cancers from 203 patients, and an unsupervised hierarchical clustering analysis, they discovered subgroups of colorectal cancers that were characterized by reduced CK8 and 20 expression, and that differed from the other groups by a shorter patient survival time. Evaluation of specific biomarkers by Kaplan-Meier analysis showed that reduced CK8 expression $(p<0.01)$ was significantly associated with a shorter patient survival time. They concluded that reduced coexpression of CK8 and CK20 may indicate the occurrence of an EMT in the development of more aggressive colorectal cancers (Knosel et al., 2006). 
Cell migration is necessary for cancer invasion into the surrounding stroma. Another factor important for invasion is degradation of the extracellular matrix by matrix metalloproteases (MMPs). During EMT, the expression of junction proteins is lost along with other epithelial characteristics, which results in a loss of the ability of tumor cells to interact with each other, thereby promoting a migratory phenotype (Fuxe et al., 2010). Indeed, loss of desmosomal proteins has been shown to increase epithelial cell migration (Rieger-Christ et al., 2005; South et al., 2003). CKs connect with desmosomes to form extensive cadherin-mediated cytoskeletal structures (Buhler \& Schaller, 2005; Kouklis et al., 1994; Smith \& Fuchs, 1998). These data would therefore be consistent with the idea that the loss of CK expression can promote an invasive phenotype through a mechanism that elevates migratory ability by down-regulating desmosomal proteins. In agreement with this hypothesis, it was reported that transfection of CK19 into squamous cell carcinoma cells led to a decrease in invasiveness due to a reduced migratory ability (Crowe et al., 1999). In addition, CK18-transfected breast cancer cells showed low invasive ability because the expressed exogenous CK18 dimerized with endogenous CK8, and resulted in the up-regulation of two desmosomal proteins, desmoglein and plakoglobin as well as E-cadherin (Buhler \& Schaller, 2005).

In parallel with the above-described effects, cells undergoing EMT boost their migratory capacity through increased expression of mesenchymal proteins including vimentin and $\alpha$ SMA (Fuxe et al., 2010). Overexpression of vimentin in cancer correlates well with accelerated tumor growth, invasion, and poor prognosis (Satelli \& Li, 2011). Interestingly, a decrease in vimentin expression was observed in breast cancer cells transfected with CK18 (Buhler \& Schaller, 2005). There may be mutually exclusive expression of CKs and vimentin in situations such as EMT, and up-regulation of vimentin could be one possible mechanism by which loss of CKs induces the migratory and invasive ability of cancer cells.

Thus, tumor cells undergoing EMT acquire the capacity to migrate and invade the surrounding stroma and subsequently spread via blood and lymphatic vessels to distant sites (Fuxe et al., 2010). Accumulating evidence will further enhance our understanding of an important role of CKs in EMT-induced cancer progression.

\section{Extracellular release of cytokeratins}

Until recently even a large number of biomedical researchers found it difficult to believe that highly stable cytoskeletal proteins are released from the cytoplasm into the extracellular space. However, the organization of the IF network is extremely dynamic and IF proteins are indeed released extracellularly through several mechanisms. Post-translational modifications of CKs, the presence of soluble CK pools, and disruption as well as reorganization of cell membranes and/or CK networks, all appear to contribute to the extracellular release of highly insoluble CKs (Coulombe \& Omary, 2002; Karantza, 2011; Omary et al., 2006).

\subsection{Post-translational modification of cytokeratins and the soluble cytokeratin pool}

The type I and type II CKs, as well as other cytoplasmic IF proteins, consist of a common tripartite domain structure, with non-helical amino terminal (head) and carboxyl terminal (tail) domains that flank a central a-helical rod domain consisting of $\sim 310$ amino acids. The amino acid sequence of the rod domain is highly conserved, whereas the size and sequence of the amino-terminal head and carboxyl-terminal tail domains vary extensively between 
individual IFs. Type I and type II CKs associate to form obligate heterodimers, and antiparallel heterodimers (referred to as tetramers) polymerize in a staggered fashion to form protofilaments ( $3 \mathrm{~nm}$ in diameter), which unite to form protofibrils (4- $5 \mathrm{~nm}$ in diameter), and then to IFs (10 nm in diameter) (Fig. 6; also see "2.1 Cytokeratin networks"). This IF structure that is $10 \mathrm{~nm}$ in diameter exhibits remarkable chemical stability, resisting high temperature, high salt and detergent solubilization (Alberts et al., 2008; Steinert et al., 1993).

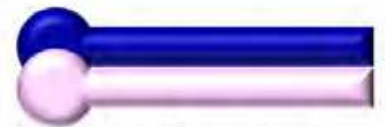

(a) coiled-coil heterodimer

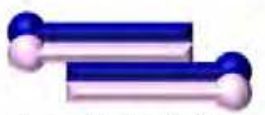

(b) Two coiled-coil dimers form a staggered tetramer

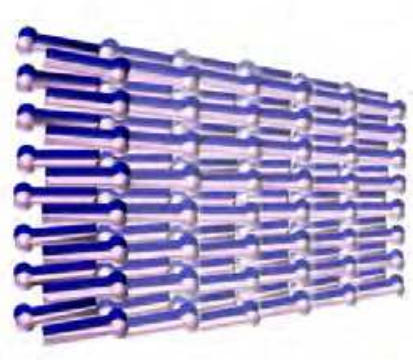

(c) Eight tetramers form an IF filament of $10 \mathrm{~nm}$ in diameter

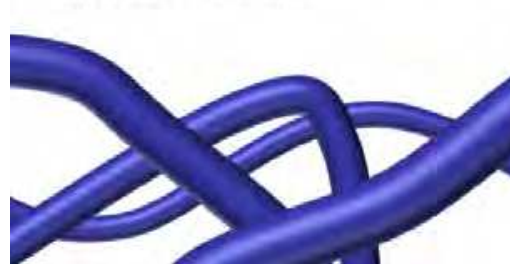

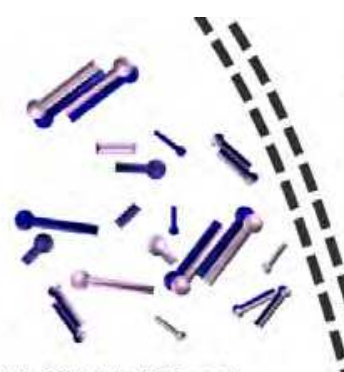

(e)

e) Soluble CK pool

\section{(f) Extracellular release}

- Disturbance of cell membrane

- Cell division

- Surgical intervention

- Apoptosis

- Necrosis

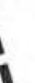

(
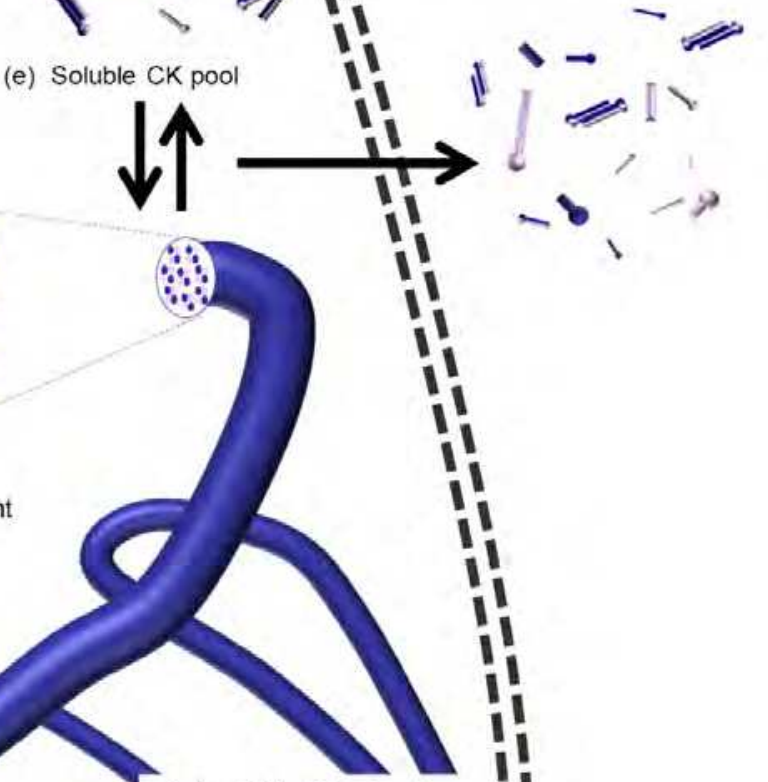

(d) Insoluble IF network

(a) Two different types (type I and type II) of CK monomers (the COOH-terminals are drawn as balls for orientation) pair in parallel through the central rod domain, termed the $\alpha$-helical region, of each monomer, forming a "coiled-coil heterodimer."

(b) Two dimers form an antiparallel tetramer of four polypeptide chains. This tetramer is the fundamental soluble subunit of cytokeratin IFs. Within each tetramer, the two dimers are mutually offset allowing one tetramer to associate with another tetramer.

(c) Tetramers line up together, with eight tetramers in a cross section, ultimately forming a filament that is 10-nm in diameter, which is the component polypeptide of the insoluble IF network (d)

(e) A small fraction of total CKs form a soluble pool in the cytoplasm.

(f) Upon cell division, cell death (apoptosis or necrosis) or disruption of the cell membrane, the soluble fraction of $\mathrm{CKs}$ is released into the circulation.

Fig. 6. Extracellular release of IF proteins 
IF proteins, such as type III vimentin and type IV neurofilaments, undergo phosphorylation during the G2/M phase of the cell cycle, which plays a key role in the assembly and disassembly of IF subunits (Sihag et al., 2007). Both type I and type II CKs also undergo phosphorylation. Chou et al. first reported that asynchronously growing human colon cancer HT29 cells (G0/G1 phase of the cell cycle) have a substantial pool of soluble CK that constitutes $\sim 5 \%$ of the total cellular CK. Several other cell lines showed a similar, significant pool of soluble cytosolic CK8/CK18. The arrest of cells in the G2/M phase of the cell cycle was associated with a concurrent increase in CK solubility. CK8/CK18 was shown to be in dimeric or tetrameric forms, but primarily in tetrameric keeping the ability of assembly (Chou et al., 1993; Omary et al., 2006). Subsequently, Liao et al. demonstrated that CKassociated 14-3-3 proteins act as a soluble co-factor by binding to phosphorylated CK8/CK18 and sequestering them into a soluble fraction. In case of vimentin, the phosphorylation-induced disassembly of vimentin filaments results in the release of tetrameric subunits, suggesting that assembly and disassembly are phosphorylationregulated events (Eriksson et al., 2004). Thus, the majority of CK8 and CK18 molecules form an insoluble CK network during the G1 phase of the cell cycle. During the $S$ phase and the G2/M phase, CK8 and CK18 become hyperphosphorylated, resulting in an increase in the soluble pool of CKs. Dephosphorylation of CKs at the end of mitosis returns CK8 and CK18 into a G1 cytoskeletal network (Liao \& Omary, 1996; Omary et al., 2006).

\subsection{Mechanisms of cytokeratin release}

Several mechanisms by which insoluble macromolecule IF network components are released into the circulation, have been suggested. In these mechanisms the presence of soluble CK pools, as well as disruption and reorganization of cell membranes and/or CK networks appear to contribute to the extracellular release of largely insoluble CKs (Chou et al., 1993; Omary et al., 2006). CKs have been found in extracellular spaces both in vitro and in vivo, in conditioned culture medium to circulating human blood. CK release is observed during cell growth/cell divisions, after surgical intervention, and upon cell death induction (e.g., radiation therapy and/or cytotoxic chemotherapy) (Bauer et al., 1986; Bjorklund \& Bjorklund, 1983; Brabon et al., 1984; Caulin et al., 1997; Dohmoto et al., 2000; Dohmoto et al., 2001; Sheard et al., 2002; Tinnemans et al., 1995).

CKs are released during cell division. In early 1980s, Bjorklund reported that in cultured uterine cervix cancer HeLa cells, TPA (i.e. CK8, CK18 and CK19) is seen in perinuclear area during the early $S$ phase. After cell division TPA becomes externalized leaving the cell free of visible TPA, while TPA levels in the culture medium increase at this stage (Bjorklund \& Bjorklund, 1983). Upon estrogen stimulation, breast cancer MCF-7 cells release CKs, part of which localized to the cell surface, into the tissue culture medium (Brabon et al., 1984). TPA is found in the systemic circulation during perioperative period. Twenty patients with lung cancer or gastric cancer who underwent curative surgery were prospectively monitored for serum TPA prior to surgery and during the subsequent year. Serum levels of TPA immediately fell after surgery, and following the initial 2 weeks after complete removal of tumors, serum TPA rise to some extent. This temporal increment is interpreted as being caused by tissue repair and cell proliferation (Bauer et al., 1986).

Post-translational modification and protein processing on CKs during apoptosis have been intensively studied. CK aggregation in the cytoplasm is one of earliest events of apoptosis in 
epithelial cells, while at a later stage CKs degrade (Tinnemans et al., 1995). These CK filament reorganizations during apoptosis are accompanied by caspase cleavage of type I CKs (Caulin et al., 1997). Using MCF-7 cells, Sheard et al. revealed TPS (i.e., CK18) and Cyfra 21-1 (CK19) are abundantly released during apoptosis and the release precedes DNA fragmentation (Sheard et al., 2002). We also observed mRNA expression of CK19 is essential in Cyfra 21-1 formation and caspase 3 plays an important role in producing Cyfra 21-1 in human lung cancer cell lines (Dohmoto et al., 2000; Dohmoto et al., 2001). Kramer described that large amounts of CK18 are released into extracellular space during necrosis induced by oligomycin, and that release of CK18 is a marker of epithelial cell death and not a marker of apoptosis (Kramer et al., 2004).

\section{Circulating cytokeratins and their clinical significance}

Clinically, circulating molecules related to CK8, CK18 or CK19 have widely been used as tumor markers of various types of malignancies. Here we briefly review CK-related tumor markers and discuss issues to be considered when evaluating circulating CK-related molecules, focusing especially on CK8.

\subsection{Circulating cytokeratin-related molecules and their biological and clinical relevance}

CK-related circulating polypeptides have served as useful tumor markers of various epithelial malignancies. Measurement of CKs in the circulation is clinically useful for the early detection of recurrence, and for assessment of the disease response to treatment. The most widely applied CK tests are the monoclonal antibody-based assays: TPA, TPS and Cyfra 21-1.

TPA has long been used as a serological marker in various types of epithelial malignancies, e.g., lung cancer, breast cancer, colorectal cancer, head and neck cancer, and urothelial cancer (Bennink et al., 1999; Gion et al., 2000; Nicolini et al., 1995; Plebani et al., 1995; Rosati et al., 2000; Soletormos et al., 2004). TPA is a good example of a broad-spectrum CK assay, and measures CK8, CK18 and CK19 in serum samples. TPA was reported to be a highly sensitive marker of cancer patients (Mellerick et al., 1990). However, in contrast, Anquilina reported that although TPA has both a sensitivity and a specificity of $65 \%$, this may not be sufficient for discrimination between malignant and benign lung diseases (Aquilina et al., 1992).

TPS assay was proposed as an advance over TPA assay. It was claimed that serum TPS levels correlated highly with the proliferation rate of cancer cells (Buccheri \& Ferrigno, 2001). Studies of patients with lung diseases of either neoplastic or non-neoplastic origin revealed TPS sensitivity rates between 13-54\% (Correale et al., 1994; Giovanella et al., 1995; Nisman et al., 1998; Pujol et al., 1994; Pujol et al., 1996; van der Gaast et al., 1994). TPS sensitivity did not vary in NSCLC with different histology, but it did differ according to the progression of lung cancer (Giovanella et al., 1995; Pujol et al., 1996).

Cyfra 21-1 is an assay that uses two monoclonal antibodies to measure soluble CK19 fragments in the circulation, (Pujol et al., 1993). Cyfra 21-1 has been most intensively studied 
in lung cancer and head and neck cancer (Nisman et al., 1998; Yen et al., 1998). Our hypothesis regarding the mechanism of Cyfra 21-1 production was that Cyfra 21-1 release depends on CK19 expression and cell apoptosis. We tested this hypothesis using 13 lung cancer cell lines. The mRNA expression level of CK19 in these cells significantly correlated with the levels of Cyfra 21-1 in culture supernatants as measured by ELISA, as well as with intracellular protein expression of CK19 assessed by immunoblotting, and with immunopositivity of CK19 in immunohistochemical analysis. Furthermore, a specific inhibitor of caspase 3 efficiently inhibited the release of Cyfra 21-1 into culture supernatants. Based on these observations we concluded that caspase 3 plays an important role in the production of Cyfra 21-1 in lung cancer cell lines (Dohmoto et al., 2001). Pujol et al evaluated Cyfra 21-1 and TPS in 405 lung cancer patients (91 SCLC and 314 NSCLC) and in 59 patients with non-malignant lung diseases. Receiver operating characteristics (ROC) analysis, in which both the sensitivity and specificity of Cyfra 21-1 and TPS were continually examined, demonstrated that Cyfra 21-1 assay was more accurate than TPS assay for detection of both SCLC and NSCLC. The sensitivity of Cyfra 21-1 was highest for squamous cell carcinoma (0.61) and lowest for SCLC (0.36), whereas the sensitivity of TPS did not vary among histological types (overall sensitivity, 0.40). The values of both Cyfra 21-1 and TPS significantly reflected the disease stage in NSCLC. However, when multivariate analysis was performed to take into account other significant factors, only Cyfra 21-1, and not TPS, was confirmed to be an independent prognostic factor (Pujol et al., 1996).

CK18 is a useful tumor marker as evidenced by TPA and TPS assays. Type I CK18 is also a good substrate for caspases as discussed earlier in this chapter. ELISAs are now available for assay of CK18 that is cleaved at Asp396 by caspases, which can be detected using M30 and M5 monoclonal antibodies (referred to as M30), and for assay of total CK18, which can be detected using M5 and M6 monoclonal antibodies (referred to as M65) (Kramer et al., 2004; Linder et al., 2010). M30-recognized circulating CK18 is released from apoptotic cells, whereas M65-recognized CK18 reflects cell death by any cause. The ratio of caspase-cleaved to total CK18, calculated using M30- and M65-ELISAs, may provide potentially useful information regarding the mode of tumor cell death (Linder et al., 2010). The usefulness of M30 for tumor monitoring has been demonstrated by Koelink et al. They determined caspase-cleaved CK18 and total CK18 levels in the plasma of 49 colorectal cancer patients, before and after surgical resection. Both the levels of caspase-cleaved CK18 and total CK18 were related to disease stage and tumor diameter. The M30/M65 ratio decreased with tumor progression, and was also predictive of disease free survival (Koelink et al., 2009). De Petris et al. measured circulating total CK18, caspase-cleaved CK18 and Cyfra 21-1 in 200 healthy blood donors, 113 patients with non-malignant lung diseases and 179 NSCLC cases, using ELISA assays. The diagnostic accuracy of both CK18 forms in distinguishing between NSCLC and healthy blood donors was 56\%, whereas it was $94 \%$ for Cyfra 21-1. Multivariate survival analysis revealed that total CK18 was a better prognostic factor than Cyfra 21-1 or caspase-cleaved CK18. The reason why caspase-cleaved CK18 was not of prognostic value might be due, at least in part, to the greater importance of tumor necrosis compared to tumor apoptosis in this disease (De Petris et al., 2011).

The above single measurements of circulating type I CKs have significant value for the diagnosis and monitoring of patients with NSCLC. However, a single measurement of 
circulating type II CKs has not been reported as tumor markers, which prompted us to determine the clinical significance of circulating CK8 in NSCLC.

\subsection{Cytokeratin 8 as a novel tumor marker}

As described above, type II CK8 is the dominant CK in NSCLC, and circulating CK-related species have been used as a valuable tumor marker in the clinic. We hypothesized that the levels of circulating CK8 would be higher in patients with NSCLC than in patients with SCLC, and that circulating CK8 would be related to disease progression, metastases, and survival in patients with NSCLC. To test this hypothesis, we determined the serum levels of CK8 in patients with lung cancer (Fukunaga et al., 2002).

We first established an ELISA assay of CK8 using the anti-CK8 monoclonal antibody M20. We next determined the CK8 mRNA expression level of 9 NSCLC cell lines (7 adenocarcinomas and 2 squamous cell carcinomas) and 9 SCLC cell lines using a semiquantitative competitive reverse transcription-polymerase chain reaction (RT-PCR). The expression levels of CK8 mRNA were significantly higher in NSCLC cells compared with those in SCLC cells (mean \pm standard error: $60.8 \pm 16.2$ versus $9.9 \pm 2.5$ attomoles/ $\mu \mathrm{g}$ total RNA, $\mathrm{p}<0.05)$. The levels of CK8 in the culture supernatants of these cells, assayed using the established ELISA, were also significantly higher in the NSCLCs than in the SCLCs $(310.0 \pm 108.0$ versus $69.0 \pm 18.4 \mathrm{ng} / \mathrm{ml}, \mathrm{p}<0.05)$. Importantly, the expression level of CK8 mRNA significantly correlated with the measured CK8 protein levels in the culture supernatants of the 17 cell lines $(R=0.896, \mathrm{p}<0.0001)$

CK8 levels in the serum were then determined using this newly established ELISA in 70 consecutive, pathologically-proven lung cancer patients in Kagawa University (male/female, 55/15; median age, 67; performance status, 0/1/2, 16/38/16; histology, adenocarcinoma/squamous cell carcinoma/small cell carcinoma, 25/35/10; disease stage of NSCLC, I/II/III/IV, 10/11/18/21; disease stage of SCLC, limited disease/extensive disease, 4/6). CK8 serum levels were also determined in ten non-smoker normal volunteers. CK8 was detected in the serum of 56 out of 60 patients (93.3\%) with NSCLC. The levels of serum CK8 ranged between 0.0 and $595.9 \mathrm{ng} / \mathrm{ml}$. Serum levels of CK8 in NSCLC patients were significantly higher than those in SCLC patients or normal volunteers $(86.2 \pm 12.1$ versus $16.6 \pm 5.2$ versus $21.2 \pm 7.0 \mathrm{ng} / \mathrm{ml}, \mathrm{p}<0.05)$. The levels of serum CK8 in patients at the advanced stages III and IV were significantly higher than those at the early stages I and II (Fig. 7, A; Figures 7-8. Modified with permission from (Fukunaga et al., 2002)). Similarly, serum CK8 levels of patients with distant metastases were significantly higher than those with no metastases (Fig. 7, B).

A cutoff value of $50 \mathrm{ng} / \mathrm{ml}$ was determined based on the highest value observed for serum CK8 in non-smoker volunteers. Fig. 8 demonstrates that NSCLC patients with serum CK8 levels that were higher than this cut-off value showed significantly shortened survival times (Fukunaga et al., 2002).

We demonstrated higher expression levels of CK8 in NSCLC cell lines as well as in culture supernatants, and higher levels of CK8 in the serum of patients with advanced and poor prognosis NSCLC tumors. These results suggest that circulating CK8 may have potential as a novel tumor marker, especially in patients with NSCLC. 

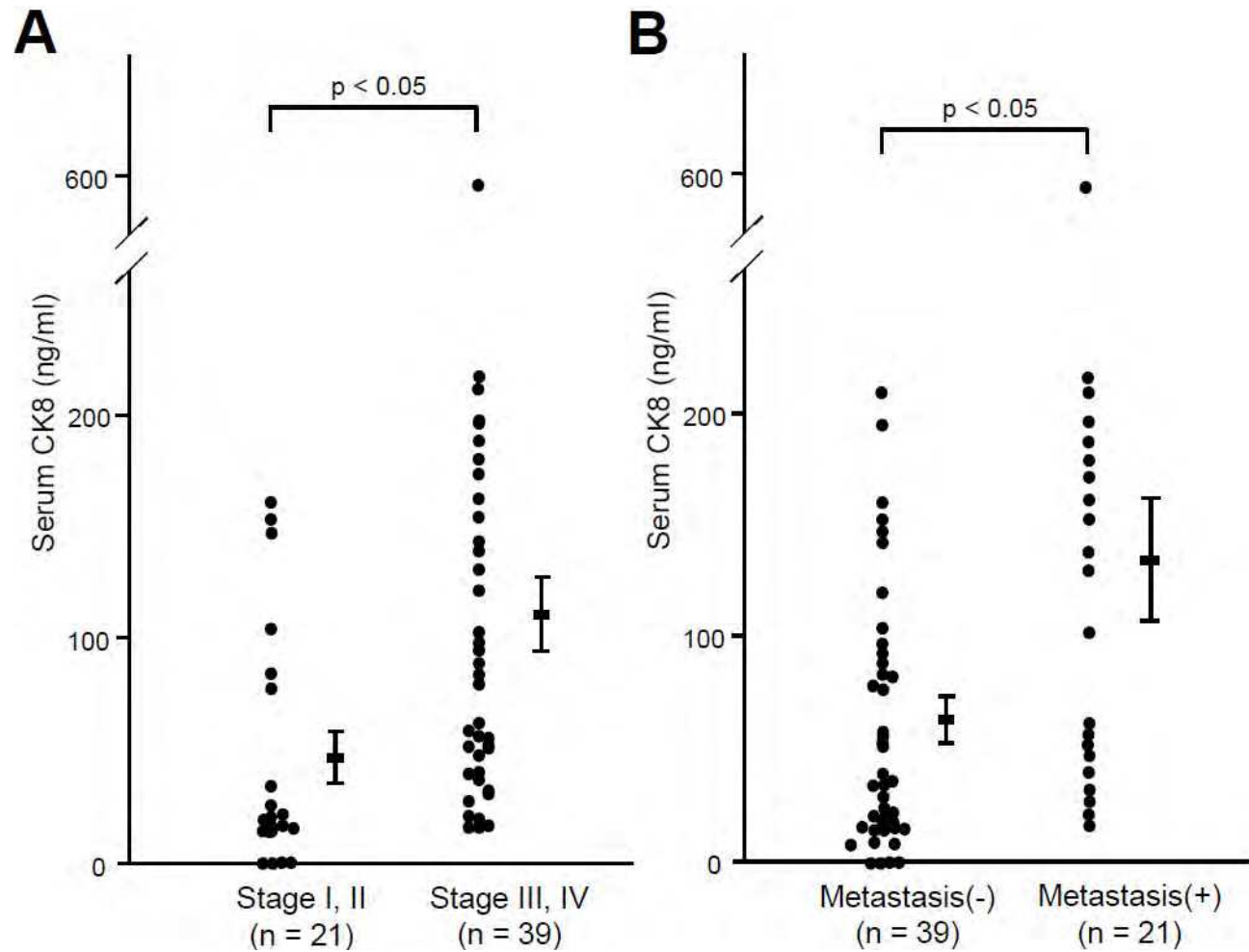

(A) Levels of CK8 in patients with NSCLC at advanced-stages were significantly higher compared with those at earlier stages. (B) Levels of CK8 in patients who had distant metastases of NSCLC were significantly higher compared with those with no distant metastases. To quantify circulating CK8, we established an indirect ELISA using a monoclonal anti-CK8 antibody (M20, purchased from Progen, Heidelberg, Germany). Data are expressed as mean values from duplicate determinations. Mean comparisons of samples were performed using the Mann-Whitney-Wilcoxon test.

Fig. 7. Relationship between tumor progression or distant metastasis and levels of CK8 in the serum of NSCLC patients. 


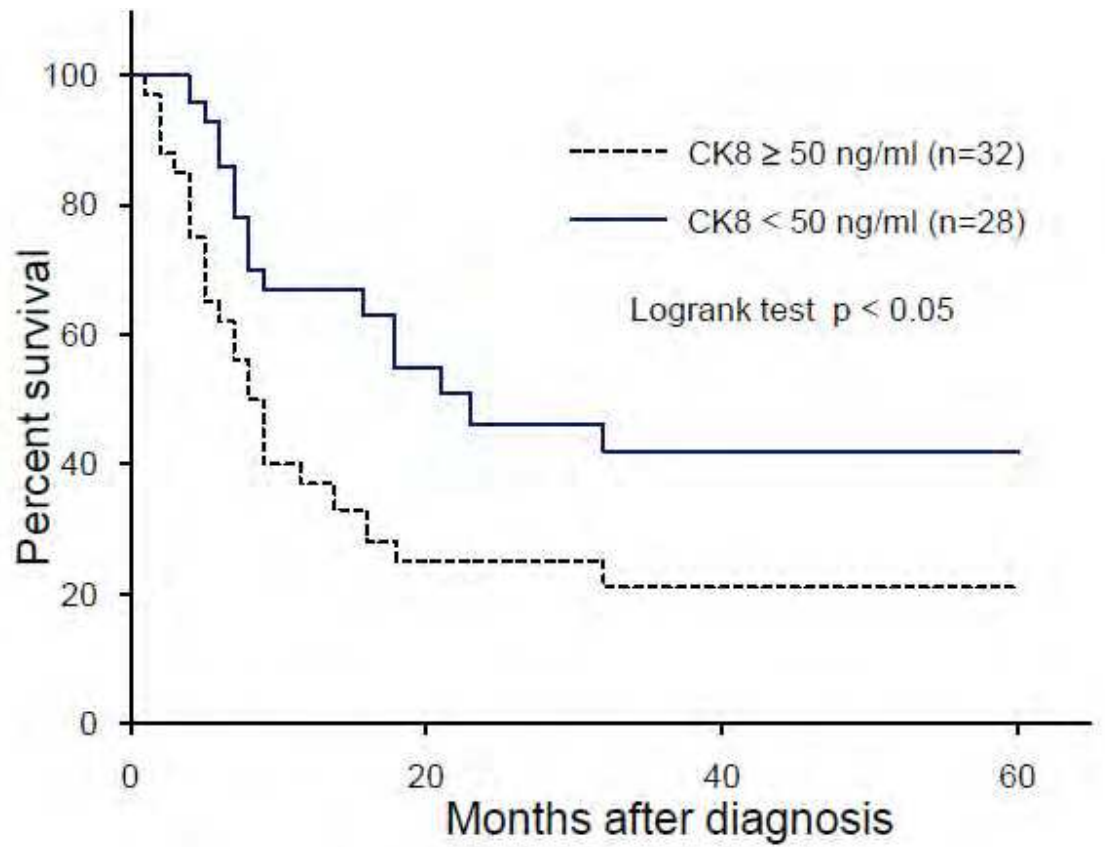

Patients with a CK8 value of $50 \mathrm{ng} / \mathrm{ml}$ or higher had a significantly shorter survival time compared with those with lower CK8 values. Survival curves were computed using the Kaplan-Meier method. Mantel's log-rank test was employed to test for equality of survival curves.

Fig. 8. Survival of all patients with NSCLC according to their serum CK8 levels.

\subsection{Nature of circulating cytokeratin-related peptides}

The nature of circulating CKs in patients with cancer has been widely believed to be CK degradation fragments, which has not been clearly elucidated (Buccheri \& Ferrigno, 2001; Pujol et al., 1993; van Dalen, 1996). However, several recent findings may provide some clues to illuminate the characteristics of CK-related molecules in the circulation.

In the cytoplasmic soluble pools, type I-type II CK tetramers appear to be the main components (Alberts et al., 2008; Chou et al., 1993). It sounds plausible that circulating type I and type II CKs may be associated, because CKs intrinsically have a self-bundling potential through their $\alpha$-helical rod domains, and form primarily heterotetramers in the cytoplasmic soluble pools (Chou et al., 1993; Coulombe \& Omary, 2002). Pendleton et al. analyzed serum samples from 24 patients with NSCLC, and detected full length protein of both CK8 and CK18 (Pendleton et al., 1994). In contrast, type I CKs are easily digested by caspases during apoptosis, and these fragments are indeed detected in the circulation as Cyfra 21-1 and as caspase-cleaved CK18 (Buccheri \& Ferrigno, 2001; Kramer et al., 2004; Linder et al., 2010; Pujol et al., 1993; Pujol et al., 1996). Unlike type I CKs, type II CKs do not appear to be good caspase substrates. Type II CK8, however, does have potential caspase recognition sequences and effector caspases can cleave CK8 as well as CK18 and CK19, which may be depending on cell types (MacFarlane et al., 2000). Biological significance of caspase 
recognition sequences in type II CK8 might be illustrated by the presence of aberrantly spliced form of CK8, detected both in lung cancer cell lines and in primary NSCLC tumors. This aberrantly spliced form lacks the caspase cleavage sequence within the linker L12 region, which may confer caspase resistance (Tojo et al., 2003). We also examined circulating CK8 by immunoprecipitation and quantitative immunoblotting from serum samples described above (Fukunaga et al., 2002), and determined that circulating CK8 is mostly ( $\sim 86 \%)$ full length protein (Ishii et al., 2008).

It has not been well understood whether circulating CK-related molecules retain biological functions. Circulation of CK-related polypeptides may not be mere end results of various cellular events and protein processing. For example, phosphorylated type III IF vimentin is released from activated macrophages in response to proinflammatory signaling and is involved in eliminating bacteria and in generating oxidative metabolites, both of which are important functions of activated macropahges (Mor-Vaknin et al., 2003). In case of CKs, we previously reported that antigenically-altered large molecule CK8 contain antigenic epitopes of a tumor marker CA19-9, suggesting that CK8 may function as a carrier protein for CA19-9 (Fujita et al., 1999). As $\alpha$-helical rod domains are essential for type I-type II heteropolymerization, it is possible that full-length type II CK8 may serve as a binding platform even if circulating type I CKs may partially degrade. Considering the numerous CK-associated proteins, it is also possible that circulating full-length CK8 may form a protein complex with other CK-associated proteins.

\section{Issues to be considered when evaluating cytokeratins in tumor cells and in the circulation}

Biological relevance of CKs has been intensively studied and myriad of evidence has become accumulated, as discussed in detail in this and other chapters. However, when evaluating these CKs and CK-related products, there are several issues we need to keep in mind (Table 3).

\begin{tabular}{|l|}
\hline Factors that influence CKs in tumor cells and in the circulation \\
\hline \hline CK-related molecules in the circulation may reflect: \\
- $\quad$ Expression levels of the individual CKs in the tumor lesions \\
- $\quad$ Decal tumor burden \\
- $\quad$ Production from non-tumorous tissues \\
\hline CKs in each tumor cell may reflect: \\
- $\quad$ Differentiation status largely depending on cell and/or tissue \\
- $\quad$ Statext \\
- $\quad$ Invasiveness and metastatic abilities \\
- $\quad$ Cell cycle and cell death \\
\hline
\end{tabular}

Table 3. Issues to be considered when evaluating CKs in tumor cells and in the circulation 
Release of CKs into circulation is a complex multistep process influenced by numerous factors. In tumors expressing CK8/CK18, total amount of CKs likely reflect tumor burden, and also affect the amount of CKs leaking from tumors into extratumoral space, especially into the circulation. Accordingly, the presence of circulating CKs per se does not necessarily reflect characters (e.g. invasiveness and/or metastatic ability) of individual cells. In other words, it is meaningless to evaluate circulating CK-related markers if the original tumors do not express such CKs. Attention need to be paid when evaluating these CK serum markers, because not all lung tumors equally express CK8, CK18 and CK19 (Barak et al., 2004; Karantza, 2011; Linder et al., 2010). Extracellular release of CKs may also be affected by cell deaths (spontaneous or treatment-induced) and cell proliferation. The mechanisms of decay of circulating CK-related products have not been well understood. Apoptotic or necrotic cells are processed by macrophages. The increased turnover of cell proliferation and cell death may overload and subsequently break the clearance mechanisms, which may lead to the accumulation of intracellular components, including CK-related molecules, in the circulation (Linder et al., 2010).

Non-tumorous tissues may become other sources of circulating CKs. Temporal elevations of TPA after surgery for gastric cancer or lung cancer were attributable to tissue repair and physiological cell proliferation as described previously in this chapter (Bauer et al., 1986). Increased serum levels of Cyfra 21-1 were observed in patients with diffuse radiation pneumonitis (inflammation in non-tumorous lung tissues caused by chest radiation therapy), suggesting inflamed lung epithelial tissues as non-cancerous source of circulating CKs (Fujita et al., 2004).

Expression of CKs may reflect differentiation status which seems to depend significantly on cell and/or tissue contexts (Moll et al., 2008; Moll et al., 1982). For example, on various types of epithelial injury, cells may switch from CK8/CK18 to additional CK7 and CK19. This increased CK expression appears to parallel the reduced differentiation (Moll et al., 2008). When tumor cells are acquiring abilities to invade, to resist apoptosis, and to disseminate thorough EMT program, decrement of epithelial markers including CKs and increment of mesenchymal markers including vimentin are often observed (Hanahan \& Weinberg, 2011). In contrast to EMT, CKs may also confer aggressiveness to cancer cells as discussed earlier in this chapter.

\section{Conclusion}

CK8 is the dominant type II IF protein, constituting the primary CK pair with type I CK18, in lung cancer especially in NSCLC. Recent studies have accumulated evidence on understanding roles of $\mathrm{CKs}$ as diagnostic markers on tumor pathology, and structural functions of CKs protecting cells from various stress and injuries.

Regulatory functions of CKs seem to be much more multifactorial in terms of cell type- and differentiation stage-dependency as well as numerous interacting factors. At present no definitive roles of CKs in tumor progression have been established, although CKs seem to regulate tumor invasion and metastases positively or negatively by a complex but not fully determined mechanisms. Hopefully future research will solve these questions. Circulating CK-related polypeptides seem to have a potential of clinically meaningful tumor markers. These candidate serum markers await a prospective evaluation in large scale clinical trials. 


\section{Acknowledgment}

We thank Ms. Takimi Tamaki and Ms. Kanako Tejima for their excellent technical assistance. The paper was supported in part by the Japan Society for the Promotion of Science (JSPS) KAKENHI (23501314 and 22790760).

\section{References}

Alberts, B., et al., (2008). The cytoskeleton. In: Molecular Bioloby of the Cell, Alberts, B., et al., pp. 965-1052, Garland Science, Taylor \& Francis Group, 978-0-8153-4106-2, Abingdon

Aquilina, R., et al., (1992). [Trials of the diagnostic potentials of TPA in tumorous and nontumorous lung pathologies in 303 cases]. Minerva Med, Vol. 83, No. 7-8, (JulAug 1992), pp. 415-9, 0026-4806 (Print) 0026-4806 (Linking)

Barak, V., et al., (2004). Clinical utility of cytokeratins as tumor markers. Clin Biochem, Vol. 37, No. 7, (Jul 2004), pp. 529-40, 0009-9120 (Print) 0009-9120 (Linking)

Bauer, T., et al., (1986). Short-term and long-term monitoring of the serum level of TPA after radical resection of gastrointestinal or lung cancer. Nucl Med Commun, Vol. 7, No. 2, (Feb 1986), pp. 121-7, 0143-3636 (Print) 0143-3636 (Linking)

Bennink, R., et al., (1999). Serum tissue polypeptide antigen (TPA): monoclonal or polyclonal radio-immunometric assay for the follow-up of bladder cancer. Anticancer Res, Vol. 19, No. 4A, (Jul-Aug 1999), pp. 2609-13, 0250-7005 (Print) 02507005 (Linking)

Bjorklund, B. \& Bjorklund, V., (1983). Specificity and basis of the tissue polypeptide antigen. Cancer Detect Prev, Vol. 6, No. 1-2, 1983), pp. 41-50

Brabon, A.C., et al., (1984). A monoclonal antibody to a human breast tumor protein released in response to estrogen. Cancer Res, Vol. 44, No. 6, (Jun 1984), pp. 2704-10, 0008-5472 (Print) 0008-5472 (Linking)

Broers, J.L., et al., (1986). Intermediate filament proteins in classic and variant types of small cell lung carcinoma cell lines: a biochemical and immunochemical analysis using a panel of monoclonal and polyclonal antibodies. J Cell Sci, Vol. 83, No., (Jul 1986), pp. 37-60, 0021-9533 (Print) 0021-9533 (Linking)

Broers, J.L., et al., (1993). Nuclear A-type lamins are differentially expressed in human lung cancer subtypes. Am J Pathol, Vol. 143, No. 1, (Jul 1993), pp. 211-20, 0002-9440 (Print) 0002-9440 (Linking)

Buccheri, G. \& Ferrigno, D., (2001). Lung tumor markers of cytokeratin origin: an overview. Lung Cancer, Vol. 34 Suppl 2, No., (Dec 2001), pp. S65-9

Buhler, H. \& Schaller, G., (2005). Transfection of keratin 18 gene in human breast cancer cells causes induction of adhesion proteins and dramatic regression of malignancy in vitro and in vivo. Mol Cancer Res, Vol. 3, No. 7, (Jul 2005), pp. 365-71, 1541-7786 (Print) 1541-7786 (Linking)

Caulin, C., et al., (1997). Caspase cleavage of keratin 18 and reorganization of intermediate filaments during epithelial cell apoptosis. J Cell Biol, Vol. 138, No. 6, (Sep 22 1997), pp. 1379-94

Chou, C.F., et al., (1993). A significant soluble keratin fraction in 'simple' epithelial cells. Lack of an apparent phosphorylation and glycosylation role in keratin solubility. $J$ Cell Sci, Vol. 105 ( Pt 2), No., (Jun 1993), pp. 433-44 
Chou, Y.H., et al., (1990). Intermediate filament reorganization during mitosis is mediated by p34cdc2 phosphorylation of vimentin. Cell, Vol. 62, No. 6, (Sep 21 1990), pp. 1063-71, 0092-8674 (Print) 0092-8674 (Linking)

Chu, Y.W., et al., (1993). Expression of complete keratin filaments in mouse L cells augments cell migration and invasion. Proc Natl Acad Sci U S A, Vol. 90, No. 9, (May 1 1993), pp. 4261-5, 0027-8424 (Print) 0027-8424 (Linking)

Chu, Y.W., et al., (1996). Experimental coexpression of vimentin and keratin intermediate filaments in human melanoma cells augments motility. Am J Pathol, Vol. 148, No. 1, (Jan 1996), pp. 63-9, 0002-9440 (Print) 0002-9440 (Linking)

Chu, Y.W., et al., (1997). Selection of invasive and metastatic subpopulations from a human lung adenocarcinoma cell line. Am J Respir Cell Mol Biol, Vol. 17, No. 3, (Sep 1997), pp. 353-60, 1044-1549 (Print) 1044-1549 (Linking)

Correale, M., et al., (1994). Clinical profile of a new monoclonal antibody-based immunoassay for tissue polypeptide antigen. Int J Biol Markers, Vol. 9, No. 4, (OctDec 1994), pp. 231-8, 0393-6155 (Print) 0393-6155 (Linking)

Coulombe, P.A. \& Omary, M.B., (2002). 'Hard' and 'soft' principles defining the structure, function and regulation of keratin intermediate filaments. Curr Opin Cell Biol, Vol. 14, No. 1, (Feb 2002), pp. 110-22

Crowe, D.L., et al., (1999). Keratin 19 downregulation by oral squamous cell carcinoma lines increases invasive potential. J Dent Res, Vol. 78, No. 6, (Jun 1999), pp. 1256-63, 00220345 (Print) 0022-0345 (Linking)

De Petris, L., et al., (2011). Diagnostic and prognostic role of plasma levels of two forms of cytokeratin 18 in patients with non-small-cell lung cancer. Eur J Cancer, Vol. 47, No. 1, (Jan 2011), pp. 131-7, 1879-0852 (Electronic) 0959-8049 (Linking)

Dohmoto, K., et al., (2000). Mechanisms of the release of CYFRA21-1 in human lung cancer cell lines. Lung Cancer, Vol. 30, No. 1, (Oct 2000), pp. 55-63

Dohmoto, K., et al., (2001). The role of caspase 3 in producing cytokeratin 19 fragment (CYFRA21-1) in human lung cancer cell lines. Int J Cancer, Vol. 91, No. 4, (Feb 15 2001), pp. 468-73

Eriksson, J.E., et al., (2004). Specific in vivo phosphorylation sites determine the assembly dynamics of vimentin intermediate filaments. J Cell Sci, Vol. 117, No. Pt 6, (Feb 29 2004), pp. 919-32, 0021-9533 (Print) 0021-9533 (Linking)

Fisher, D.Z., et al., (1986). cDNA sequencing of nuclear lamins A and C reveals primary and secondary structural homology to intermediate filament proteins. Proc Natl Acad Sci U S A, Vol. 83, No. 17, (Sep 1986), pp. 6450-4, 0027-8424 (Print) 0027-8424 (Linking)

Fuchs, E. \& Karakesisoglou, I., (2001). Bridging cytoskeletal intersections. Genes Dev, Vol. 15, No. 1, (Jan 1 2001), pp. 1-14, 0890-9369 (Print) 0890-9369 (Linking)

Fujita, J., et al., (1999). Detection of large molecular weight cytokeratin 8 as carrier protein of CA19-9 in non-small-cell lung cancer cell lines. Br J Cancer, Vol. 81, No. 5, (Nov 1999), pp. $769-73$

Fujita, J., et al., (2001). The point mutation in the promoter region and the single nucleotide polymorphism in exon 1 of the cytokeratin 19 gene in human lung cancer cell lines. Lung Cancer, Vol. 34, No. 3, (Dec 2001), pp. 387-94, 0169-5002 (Print) 0169-5002 (Linking)

Fujita, J., et al., (2004). Elevation of cytokeratin 19 fragment (CYFRA 21-1) in serum of patients with radiation pneumonitis: possible marker of epithelial cell damage. 
Respir Med, Vol. 98, No. 4, (Apr 2004), pp. 294-300, 0954-6111 (Print) 0954-6111 (Linking)

Fukunaga, Y., et al., (2002). Expression of cytokeratin 8 in lung cancer cell lines and measurement of serum cytokeratin 8 in lung cancer patients. Lung Cancer, Vol. 38, No. 1, (Oct 2002), pp. 31-8

Fuxe, J., et al., (2010). Transcriptional crosstalk between TGF-beta and stem cell pathways in tumor cell invasion: role of EMT promoting Smad complexes. Cell Cycle, Vol. 9, No. 12, (Jun 15 2010), pp. 2363-74, 1551-4005 (Electronic) 1551-4005 (Linking)

Gion, M., et al., (2000). Quantitative measurement of soluble cytokeratin fragments in tissue cytosol of 599 node negative breast cancer patients: a prognostic marker possibly associated with apoptosis. Breast Cancer Res Treat, Vol. 59, No. 3, (Feb 2000), pp. 211-21, 0167-6806 (Print) 0167-6806 (Linking)

Giovanella, L., et al., (1995). Tissue polypeptide specific antigen (tps) and cytokeratin 19 fragment (CYFRA 21.1) immunoradiometric assay in non small cell lung cancer evaluation. Q J Nucl Med, Vol. 39, No. 4, (Dec 1995), pp. 285-9, 1125-0135 (Print) 1125-0135 (Linking)

Goldstraw, P., et al., (2007). The IASLC Lung Cancer Staging Project: proposals for the revision of the TNM stage groupings in the forthcoming (seventh) edition of the TNM Classification of malignant tumours. J Thorac Oncol, Vol. 2, No. 8, (Aug 2007), pp. 706-14, 1556-1380 (Electronic) 1556-0864 (Linking)

Hanahan, D. \& Weinberg, R.A., (2011). Hallmarks of cancer: the next generation. Cell, Vol. 144, No. 5, (Mar 4 2011), pp. 646-74, 1097-4172 (Electronic) 0092-8674 (Linking)

Hendrix, M.J., et al., (1992). Coexpression of vimentin and keratins by human melanoma tumor cells: correlation with invasive and metastatic potential. J Natl Cancer Inst, Vol. 84, No. 3, (Feb 5 1992), pp. 165-74, 0027-8874 (Print) 0027-8874 (Linking)

Hutchison, C.J., (2002). Lamins: building blocks or regulators of gene expression? Nat Rev Mol Cell Biol, Vol. 3, No. 11, (Nov 2002), pp. 848-58, 1471-0072 (Print) 1471-0072 (Linking)

Ishii, T., et al., (2008). Full-length cytokeratin 8 is released and circulates in patients with non-small cell lung cancer. Tumour Biol, Vol. 29, No. 1, 2008), pp. 57-62, 1423-0380 (Electronic) 1010-4283 (Linking)

Jemal, A., et al., (2011). Global cancer statistics. CA Cancer J Clin, Vol. 61, No. 2, (Mar-Apr 2011), pp. 69-90, 1542-4863 (Electronic) 0007-9235 (Linking)

Kanaji, N., et al., (2007). Compensation of type I and type II cytokeratin pools in lung cancer. Lung Cancer, Vol. 55, No. 3, (Mar 2007), pp. 295-302, 0169-5002 (Print) 0169-5002 (Linking)

Kanaji, N., et al., (2011). Cytokeratins negatively regulate the invasive potential of lung cancer cell lines. Oncol Rep, Vol. 26, No. 4, (Oct 2011), pp. 763-8, 1791-2431 (Electronic) 1021-335X (Linking)

Karantza, V., (2011). Keratins in health and cancer: more than mere epithelial cell markers. Oncogene, Vol. 30, No. 2, (Jan 13 2011), pp. 127-38, 1476-5594 (Electronic) 0950-9232 (Linking)

Kasai, H., et al., (2005). TGF-beta1 induces human alveolar epithelial to mesenchymal cell transition (EMT). Respir Res, Vol. 6, No., 2005), pp. 56, 1465-993X (Electronic) 14659921 (Linking) 
Kim, K.H., et al., (1984). Expression of unusually large keratins during terminal differentiation: balance of type I and type II keratins is not disrupted. J Cell Biol, Vol. 99, No. 5, (Nov 1984), pp. 1872-7, 0021-9525 (Print) 0021-9525 (Linking)

Knosel, T., et al., (2006). Cytokeratin profiles identify diagnostic signatures in colorectal cancer using multiplex analysis of tissue microarrays. Cell Oncol, Vol. 28, No. 4, 2006), pp. 167-75, 1570-5870 (Print) 1570-5870 (Linking)

Koelink, P.J., et al., (2009). Circulating cell death products predict clinical outcome of colorectal cancer patients. BMC Cancer, Vol. 9, No., 2009), pp. 88, 1471-2407 (Electronic) 1471-2407 (Linking)

Kouklis, P.D., et al., (1994). Making a connection: direct binding between keratin intermediate filaments and desmosomal proteins. J Cell Biol, Vol. 127, No. 4, (Nov 1994), pp. 1049-60, 0021-9525 (Print) 0021-9525 (Linking)

Kramer, G., et al., (2004). Differentiation between cell death modes using measurements of different soluble forms of extracellular cytokeratin 18. Cancer Res, Vol. 64, No. 5, (Mar 1 2004), pp. 1751-6

$\mathrm{Ku}$, N.O., et al., (2002). Keratin binding to 14-3-3 proteins modulates keratin filaments and hepatocyte mitotic progression. Proc Natl Acad Sci U S A, Vol. 99, No. 7, (Apr 2 2002), pp. 4373-8, 0027-8424 (Print) 0027-8424 (Linking)

Li, Q.Q., et al., (2009). Twist1-mediated adriamycin-induced epithelial-mesenchymal transition relates to multidrug resistance and invasive potential in breast cancer cells. Clin Cancer Res, Vol. 15, No. 8, (Apr 15 2009), pp. 2657-65, 1078-0432 (Print) 1078-0432 (Linking)

Liao, J. \& Omary, M.B., (1996). 14-3-3 proteins associate with phosphorylated simple epithelial keratins during cell cycle progression and act as a solubility cofactor. $J$ Cell Biol, Vol. 133, No. 2, (Apr 1996), pp. 345-57, 0021-9525 (Print) 0021-9525 (Linking)

Linder, S., et al., (2010). Utilization of cytokeratin-based biomarkers for pharmacodynamic studies. Expert Rev Mol Diagn, Vol. 10, No. 3, (Apr 2010), pp. 353-9, 1744-8352 (Electronic) 1473-7159 (Linking)

MacFarlane, M., et al., (2000). Active caspases and cleaved cytokeratins are sequestered into cytoplasmic inclusions in TRAIL-induced apoptosis. J Cell Biol, Vol. 148, No. 6, (Mar 20 2000), pp. 1239-54

McKeon, F.D., et al., (1986). Homologies in both primary and secondary structure between nuclear envelope and intermediate filament proteins. Nature, Vol. 319, No. 6053, (Feb 6-12 1986), pp. 463-8, 0028-0836 (Print) 0028-0836 (Linking)

Mellerick, D.M., et al., (1990). On the nature of serological tissue polypeptide antigen (TPA); monoclonal keratin 8, 18, and 19 antibodies react differently with TPA prepared from human cultured carcinoma cells and TPA in human serum. Oncogene, Vol. 5, No. 7, (Jul 1990), pp. 1007-17, 0950-9232 (Print) 0950-9232 (Linking)

Moll, R., et al., (2008). The human keratins: biology and pathology. Histochem Cell Biol, Vol. 129, No. 6, (Jun 2008), pp. 705-33, 0948-6143 (Print) 0948-6143 (Linking)

Moll, R., et al., (1982). The catalog of human cytokeratins: patterns of expression in normal epithelia, tumors and cultured cells. Cell, Vol. 31, No. 1, (Nov 1982), pp. 11-24

Mor-Vaknin, N., et al., (2003). Vimentin is secreted by activated macrophages. Nat Cell Biol, Vol. 5, No. 1, (Jan 2003), pp. 59-63 
NCCN.org. (July 1, 2011). NCCN Clinical Practice Guidelines in Oncoloty Non-Small Cell Lung Cancer, In: World Wide Web Sites, July 31, 2011, Available from: <http://www.nccn.org/professionals/physician_gls/pdf/nscl.pdf>

Nicolini, A., et al., (1995). Usefulness of CEA, TPA, GICA, CA 72.4, and CA 195 in the Diagnosis of primary colorectal cancer and at its relapse. Cancer Detect Prev, Vol. 19, No. 2, 1995), pp. 183-95, 0361-090X (Print) 0361-090X (Linking)

Nisman, B., et al., (1998). Evaluation of tissue polypeptide specific antigen, CYFRA 21-1, and carcinoembryonic antigen in nonsmall cell lung carcinoma: does the combined use of cytokeratin markers give any additional information? Cancer, Vol. 82, No. 10, (May 15 1998), pp. 1850-9, 0008-543X (Print) 0008-543X (Linking)

Omary, M.B., et al., (2006). "Heads and tails" of intermediate filament phosphorylation: multiple sites and functional insights. Trends Biochem Sci, Vol. 31, No. 7, (Jul 2006), pp. 383-94, 0968-0004 (Print) 0968-0004 (Linking)

Oshima, R.G., (2002). Apoptosis and keratin intermediate filaments. Cell Death Differ, Vol. 9, No. 5, (May 2002), pp. 486-92

Pendleton, N., et al., (1994). Simple cytokeratins in the serum of patients with lung cancer: relationship to cell death. Eur J Cancer, Vol. 30A, No. 1, 1994), pp. 93-6

Plebani, M., et al., (1995). Clinical evaluation of seven tumour markers in lung cancer diagnosis: can any combination improve the results? Br J Cancer, Vol. 72, No. 1, (Jul 1995), pp. 170-3, 0007-0920 (Print) 0007-0920 (Linking)

Pujol, J.L., et al., (1994). Clinical evaluation of serum tissue polypeptide-specific antigen (TPS) in non-small cell lung cancer. Eur J Cancer, Vol. 30A, No. 12, 1994), pp. 176874, 0959-8049 (Print) 0959-8049 (Linking)

Pujol, J.L., et al., (1993). Serum fragment of cytokeratin subunit 19 measured by CYFRA 21-1 immunoradiometric assay as a marker of lung cancer. Cancer Res, Vol. 53, No. 1, (Jan 1 1993), pp. 61-6

Pujol, J.L., et al., (1996). Cytokeratins as serum markers in lung cancer: a comparison of CYFRA 21-1 and TPS. Am J Respir Crit Care Med, Vol. 154, No. 3 Pt 1, (Sep 1996), pp. 725-33, 1073-449X (Print) 1073-449X (Linking)

Quinlan, R.A., et al., (1985). Patterns of expression and organization of cytokeratin intermediate filaments. Ann N Y Acad Sci, Vol. 455, No., 1985), pp. 282-306

Rieger-Christ, K.M., et al., (2005). Restoration of plakoglobin expression in bladder carcinoma cell lines suppresses cell migration and tumorigenic potential. $\mathrm{Br} \mathrm{J}$ Cancer, Vol. 92, No. 12, (Jun 20 2005), pp. 2153-9, 0007-0920 (Print) 0007-0920 (Linking)

Rodriguez, E. \& Lilenbaum, R.C., (2010). Small cell lung cancer: past, present, and future. Curr Oncol Rep, Vol. 12, No. 5, (Sep 2010), pp. 327-34, 1534-6269 (Electronic) 15233790 (Linking)

Rosati, G., et al., (2000). Use of tumor markers in the management of head and neck cancer. Int J Biol Markers, Vol. 15, No. 2, (Apr-Jun 2000), pp. 179-83, 0393-6155 (Print) 03936155 (Linking)

Satelli, A. \& Li, S., (2011). Vimentin in cancer and its potential as a molecular target for cancer therapy. Cell Mol Life Sci, Vol. 68, No. 18, (Sep 2011), pp. 3033-46, 1420-9071 (Electronic) 1420-682X (Linking) 
Schaller, G., et al., (1996). Elevated keratin 18 protein expression indicates a favorable prognosis in patients with breast cancer. Clin Cancer Res, Vol. 2, No. 11, (Nov 1996), pp. 1879-85, 1078-0432 (Print) 1078-0432 (Linking)

Sheard, M.A., et al., (2002). Release of cytokeratin-18 and -19 fragments (TPS and CYFRA 211) into the extracellular space during apoptosis. J Cell Biochem, Vol. 85, No. 4, 2002), pp. 670-7

Shih, J.Y. \& Yang, P.C., (2011). The EMT regulator slug and lung carcinogenesis. Carcinogenesis, Vol., No., (Jun 30 2011), pp., 1460-2180 (Electronic) 0143-3334 (Linking)

Sihag, R.K., et al., (2007). Role of phosphorylation on the structural dynamics and function of types III and IV intermediate filaments. Exp Cell Res, Vol. 313, No. 10, (Jun 10 2007), pp. 2098-109, 0014-4827 (Print) 0014-4827 (Linking)

Simon, G.R. \& Turrisi, A., (2007). Management of small cell lung cancer: ACCP evidencebased clinical practice guidelines (2nd edition). Chest, Vol. 132, No. 3 Suppl, (Sep 2007), pp. 324S-339S, 0012-3692 (Print) 0012-3692 (Linking)

Smith, E.A. \& Fuchs, E., (1998). Defining the interactions between intermediate filaments and desmosomes. J Cell Biol, Vol. 141, No. 5, (Jun 1 1998), pp. 1229-41, 0021-9525 (Print) 0021-9525 (Linking)

Soletormos, G., et al., (2004). Monitoring different stages of breast cancer using tumour markers CA 15-3, CEA and TPA. Eur J Cancer, Vol. 40, No. 4, (Mar 2004), pp. 481-6, 0959-8049 (Print) 0959-8049 (Linking)

South, A.P., et al., (2003). Lack of plakophilin 1 increases keratinocyte migration and reduces desmosome stability. J Cell Sci, Vol. 116, No. Pt 16, (Aug 15 2003), pp. 3303-14, 00219533 (Print) 0021-9533 (Linking)

Steinert, P.M., et al., (1993). Conservation of the structure of keratin intermediate filaments: molecular mechanism by which different keratin molecules integrate into preexisting keratin intermediate filaments during differentiation. Biochemistry, Vol. 32, No. 38, (Sep 28 1993), pp. 10046-56, 0006-2960 (Print) 0006-2960 (Linking)

Takeyama, Y., et al., (2010). Knockdown of ZEB1, a master epithelial-to-mesenchymal transition (EMT) gene, suppresses anchorage-independent cell growth of lung cancer cells. Cancer Lett, Vol. 296, No. 2, (Oct 28 2010), pp. 216-24, 1872-7980 (Electronic) 0304-3835 (Linking)

Tinnemans, M.M., et al., (1995). Alterations in cytoskeletal and nuclear matrix-associated proteins during apoptosis. Eur J Cell Biol, Vol. 68, No. 1, (Sep 1995), pp. 35-46, 01719335 (Print) 0171-9335 (Linking)

Tojo, Y., et al., (2003). Aberrant messenger RNA splicing of the cytokeratin 8 in lung cancer. Lung Cancer, Vol. 42, No. 2, (Nov 2003), pp. 153-61, 0169-5002 (Print) 0169-5002 (Linking)

Ueda, Y., et al., (1999). Expression of cytokeratin 19 mRNA in human lung cancer cell lines. Int J Cancer, Vol. 81, No. 6, (Jun 11 1999), pp. 939-43

van Dalen, A., (1996). Significance of cytokeratin markers TPA, TPA (cyk), TPS and CYFRA 21.1 in metastatic disease. Anticancer Res, Vol. 16, No. 4B, (Jul-Aug 1996), pp. 2345-9

van der Gaast, A., et al., (1994). Prognostic significance of tissue polypeptide-specific antigen (TPS) in patients with advanced non-small cell lung cancer. Eur J Cancer, Vol. 30A, No. 12, 1994), pp. 1783-6, 0959-8049 (Print) 0959-8049 (Linking) 
Woelfle, U., et al., (2004). Down-regulated expression of cytokeratin 18 promotes progression of human breast cancer. Clin Cancer Res, Vol. 10, No. 8, (Apr 15 2004), pp. 2670-4, 1078-0432 (Print) 1078-0432 (Linking)

Yamashiro, Y., et al., (2010). Ectopic coexpression of keratin 8 and 18 promotes invasion of transformed keratinocytes and is induced in patients with cutaneous squamous cell carcinoma. Biochem Biophys Res Commun, Vol. 399, No. 3, (Aug 27 2010), pp. 365-72, 1090-2104 (Electronic) 0006-291X (Linking)

Yee, D.S., et al., (2010). The Wnt inhibitory factor 1 restoration in prostate cancer cells was associated with reduced tumor growth, decreased capacity of cell migration and invasion and a reversal of epithelial to mesenchymal transition. Mol Cancer, Vol. 9, No., 2010), pp. 162, 1476-4598 (Electronic) 1476-4598 (Linking)

Yen, T.C., et al., (1998). A study of a new tumour marker, CYFRA 21-1, in squamous cell carcinoma of the head and neck, and comparison with squamous cell carcinoma antigen. Clin Otolaryngol Allied Sci, Vol. 23, No. 1, (Feb 1998), pp. 82-6, 0307-7772 (Print) 0307-7772 (Linking)

Youlden, D.R., et al., (2008). The International Epidemiology of Lung Cancer: geographical distribution and secular trends. J Thorac Oncol, Vol. 3, No. 8, (Aug 2008), pp. 819-31, 1556-1380 (Electronic) 1556-0864 (Linking) 


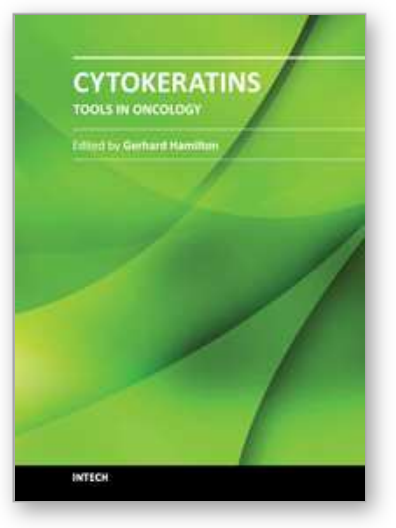

\author{
Cytokeratins - Tools in Oncology \\ Edited by Dr. Gerhard Hamilton
}

ISBN 978-953-51-0047-8

Hard cover, 158 pages

Publisher InTech

Published online 29, February, 2012

Published in print edition February, 2012

The first chapters of the volume "Cytokeratins - Tools in Oncology" discuss multiple functions of cytokeratins in organization of the intermediary filaments in normal intestine and liver as well as microfold $L$ cells and the usability of cytokeratins 7, 8 and 20 in tumor diagnosis in detail. Epithelial to mesenchymal transition as a mechanism important in pathogenesis is touched in another chapter, followed by several articles dealing with the role of cytokeratins for detection of disseminated tumor cells and as response markers during chemotherapy. This book is therefore destined to all cancer researchers and therapists who want to understand the diagnostic application of cytokeratins in histology and, especially, the use of anti-cytokeratin antibodies to identify viable residual tumor cells accounting for a higher risk of tumor recurrence or cancer cells responding to chemotherapy, respectively.

\title{
How to reference
}

In order to correctly reference this scholarly work, feel free to copy and paste the following:

Nobuhiro Kanaji, Akihito Kubo, Shuji Bandoh, Tomoya Ishii,Jiro Fujita, Takuya Matsunaga and Etsuro Yamaguchi (2012). Cytokeratin 8: The Dominant Type II Intermediate Filament Protein in Lung Cancer, Cytokeratins - Tools in Oncology, Dr. Gerhard Hamilton (Ed.), ISBN: 978-953-51-0047-8, InTech, Available from: http://www.intechopen.com/books/cytokeratins-tools-in-oncology/cytokeratin-8-the-dominant-type-iiintermediate-filament-protein-in-lung-cancer

\section{INTECH}

open science | open minds

\author{
InTech Europe \\ University Campus STeP Ri \\ Slavka Krautzeka 83/A \\ 51000 Rijeka, Croatia \\ Phone: +385 (51) 770447 \\ Fax: +385 (51) 686166 \\ www.intechopen.com
}

\author{
InTech China \\ Unit 405, Office Block, Hotel Equatorial Shanghai \\ No.65, Yan An Road (West), Shanghai, 200040, China \\ 中国上海市延安西路65号上海国际贵都大饭店办公楼 405 单元 \\ Phone: +86-21-62489820 \\ Fax: $+86-21-62489821$
}


(C) 2012 The Author(s). Licensee IntechOpen. This is an open access article distributed under the terms of the Creative Commons Attribution 3.0 License, which permits unrestricted use, distribution, and reproduction in any medium, provided the original work is properly cited. 